NBER WORKING PAPER SERIES

\title{
UNEMPLOYMENT-RATE DYNAMICS AND PERSISTENT UNEMPLOYMENT UNDER \\ RATIONAL EXPECTATIONS
}

\author{
Michael R. Darby \\ John C. Haltiwanger \\ Mark W. Plant
}

Working Paper No. 1558

\author{
NATIONAL BUREAU OF ECONOMIC RESEARCH \\ 1050 Massachusetts Avenue \\ Cambridge, MA 02138 \\ February 1985
}

The research reported here is part of the NBER's research program in Labor Studies. Any opinions expressed are those of the authors and not those of the National Bureau of Economic Research. 
NBER Working Paper \#1558

February 1985

\section{Unemployment-Rate Dynamics and \\ Persistent Unemployment Under \\ Rational Expectations}

\section{ABSTRACT}

This paper develops a model of unemployment rate dynamics that provides an explanation of persistent cyclical unemployment that does not involve persistent expectational errors or other nonoptimizing behavior. Our results are based on the interaction of search dynamics and inventory adjustments. An important element in these dynamics appears to be heterogeneity in the labor force which can be characterized as consisting of a relatively small group of high turnover individuals who comprise the bulk of normal unemployment and a larger group of low turnover individuals who dominate movements in cyclical unemployment. Our empirical results provide support for this theory as we demonstrate that the appropriately measured probability of becoming employed during a recovery falls relative to normal because of the unusually high proportion of low turnover individuals who have lost "permanent" jobs. As a result, recovery is much slower than is indicated by normal relationships although each individual is searching optimally.

Michael R. Darby Department of Economics University of California, Los Angeles Los Angeles, CA 90024 (213) 825-3343

John C. Haltiwanger Department of Economics University of California, Los Angeles Los Angeles, CA 90024 (213) 825-6619

Mark W. Plant

Department of Economics University of California, Los Angeles Los Angeles, CA 90024

(213) 825-3847 
Forthcoming in the American

Economic Review, 1985.

D9: November 14, 1984

Not for quotation without

the authors' permission.

UNEMPLOYMENT-RATE DYNAMICS AND

PERSISTENT UNEMPLOYMENT UNDER RATIONAL EXPECTATIONS

\author{
Michael R. Darby \\ University of California, Los Angeles \\ National Bureau of Economlc Research \\ John Haltiwanger \\ University of California, Los Angeles \\ Mark Plant* \\ University of California, Los Angeles
}

Macroeconomists typically build models of the determination of real output with unemployment-rate movements explained, if at all, by an appended Okun's Law relationship. In this paper we show that this approach is misleading because $1 t$ misses important sources of persistence in cyclical unemployment -- and hence - real output. In particular, we show that unemployment-rate dynamics imply "humped-shaped" cyclical unemployment characterized by persistence even though unemployed workers have faulty Information on wage rates for only a comparatively brief period of time. This result is based on the interaction of two stock or state variables inventories and cyclically unemployed workers - which result in a brief

*The authors acknowledge helpful comments from Sean Beckett1, Sebastian Edwards, Maxwel1 Fry, John J. McCall, members of the UCLA Money Workshop, and seminar participants at the UCLA Institute of Industrial Relations. The latter Institute and the National Sclence Foundation have provided financial support for this research. Able research assistance was provided by Zaki Eusufzal, Joel Lander, and Maria Sison. Any opinions expressed are the opinions of the authors and not of any institutions with which they are affiliated; this is not a report of the National Bureau of Economic Research. 
economic shock having a prolonged effect on the economy.

In the first section of the paper we develop the partial-adjustment equation which governs the evolution of the unemployment rate. We show that if Individuals differ significantly in their probability of leaving unemployment, unemployment dynamics imply a much slower recovery from recession than would be implied by probability values observed in normal times.

In the second section of the paper we develop new empirical measures of the fraction of the labor force who become unemployed each month and the probability that an unemployed person w111 become employed or leave the labor force in a month's time. These measures and alternatives -- equivalent if all individual probabilities are the same -- are used to demonstrate that the unemployed differ substantially in their individual probabilities of leaving unemployment. We can broadly characterize the labor force as consisting of two groups: The first group consists of recent entrants into the labor market who are in the process of job shopping and other individuals who have selected careers in sectors (occupational or industrial) that involve low accumulation of specific capital. This group is characterized by high rates of entry into unemployment and high probability of leaving $1 \mathrm{t}$; in normal times, the bulk of unemployment comes from this group. The second group consists of individuals with high degrees of specific human capital and "permanent" jobs; so they rarely become unemployed but search for a long time to find a replacement job when they do become unemployed. Loss of "pernanent" jobs wl11 be more prevalent during recessions because firms in declining industries find it optimal to accelerate eventual reductions in their labor force at such times. The slow search process of this second group implies that they dominate cyclical unemployment during the recovery from recessions. 
Further empirical work reported in the third section of the paper supports the following macroeconomlc parable: Money shocks do not directly effect the proximate determinates of unemployment but do so indirectly through inventorles. High inventories (relative to sales) lead to abnormally and temporarily high rates of entry of both groups into unemployment. The high Inventories also may mildy and temporarily depress the probability of leaving unemployment. The excess unemployment among the high probability group is quickly ellminated, but those who have lost permanent jobs take many months to find a new fob even though each individual's monthiy probability of success is no lower that would be the case in normal times. Thus, individual maximizing behavior leads to substantially persistent effects on cyclical unemployment and output.

\section{Unemployment Dynamics and Persistence}

In this section we demonstrate that the logic of the standard search model implies persistent cyclical unemployment as a result of a single-period forecast error on the part of searching workers. In this theoretical exposition of unemployment dynamics we abstract from the notion that some of the unemployed may not be searchers, but instead may be on temporary layoff, expecting recall. We do this in order to emphasize the separate role of search dynamics in ylelding persistent effects from uncorrelated errors. Initially we assume that all workers are identical.

\section{I.A. Identical Workers}

The dynamics of the unemployment rate can be described by a simple discrete time model. Let $u$ represent the unemployment rate, $s$ be the number of unemployed searchers, and $n$ be the labor force. By definition: 


$$
\mathrm{u}=\mathrm{s} / \mathrm{n} \text {. }
$$

It follows directly that

$$
\Delta \mathrm{u}=\frac{1}{\mathrm{n}} \Delta \mathrm{s}-\frac{1}{\mathrm{n}} \frac{\mathrm{s}-1}{\mathrm{n}-1} \Delta \mathrm{n}
$$

and therefore:

$$
\Delta u=\frac{1}{n} \Delta s-\frac{\gamma}{1+\gamma} u_{-1}
$$

where $\gamma=\Delta \mathrm{n} / \mathrm{n}_{-1}$ is the growth rate of the labor force. Define the search flow $f$ as the rate (per period) at which people begin search and let $\pi$ be the probability per period that a searcher will become employed (or leave the labor force). 1 The change in searchers $\Delta s$ is simply the inflow during the period less the outflow:

$$
\Delta \mathrm{u}=\frac{1}{\mathrm{n}}\left(\mathrm{f}-\pi \mathrm{s}_{-1}\right)-\frac{\gamma}{1+\gamma} \mathrm{u}_{-1}
$$

Note that $s_{-1} / \mathrm{n}=\mathrm{u}_{-1} \mathrm{n}_{-1} / \mathrm{n}=\mathrm{u}_{-1} /(1+\gamma)$ and 1 et $\phi=\mathrm{f} / \mathrm{n}$ denote the search rate (the fraction of the labor force beginning search in the current period); then

$$
\Delta \mathrm{u}=\phi-\frac{\pi+\gamma}{1+\gamma} \mathrm{u}_{-1}
$$

The growth-adjusted probability $\pi^{*}=(\pi+\gamma) /(1+\gamma)$ is dominated by $\pi$ empirical1y, so we can Interpret equation (5) as saying that the unemployment rate rises (or falls) as the search rate exceeds (is less than) the adjusted probability of employment times the lagged unemployment rate.

The natural unemployment rate $\bar{u}$ is found by setting $\Delta u=0$ for the normal or long-run equilibrium values $\bar{\phi}, \bar{\pi}$, and $\bar{\gamma}$ :

${ }^{1}$ Clark and Summers (1979) and Ries (1984) Indicate that the probability of leaving the labor force (temporarily) is substantial for unemployed people in certain demographic groups -- especially married women and teenagers. 


$$
\overline{\mathrm{u}}=\bar{\phi} \frac{1+\bar{\gamma}}{\bar{\pi}+\bar{\gamma}}=\bar{\phi} / \bar{\pi} *
$$

That 1s, the natural unemployment rate is the product of the normal search rate $\bar{\phi}$ and adjusted duration of search $\left(1 / \bar{\pi}^{*}\right) .^{2}$ For example, suppose that under normal conditions two percent of the labor force begins the search process each month, the probability of finding employment in a month is one third (1.e., the expected duration of search 1 s $1 / \pi$ or 3 months), and the growth rate of the labor force is $0.002 /$ month. Then the natural unemployment rate is

$$
\vec{u}=0.020 \frac{1.002}{0.3353}=0.020 \times 2.988=0.0598
$$

This is close to the 6 percent rate which we would obtain by ignoring the growth adjustment and simply taking the ratio of $\bar{\phi}$ to $\bar{\pi}$. Denote cyclical components with circumflexes so that $\hat{\phi}=\phi-\bar{\phi}$, $\hat{\pi^{*}}=\pi^{*}-\bar{\pi}^{*}$, and $\hat{u}=u-\vec{u}$. Then combining equations (5) and (6) and manipulating the result yields ${ }^{3}$

${ }^{2}$ Actually $\bar{\phi}$ and $\bar{\pi}$ are proportionally equal underestimates of the true continuous time rates because, in the former case, Individuals who both enter and leave unemployment between surveys are omitted and, in the latter case, the effects of continuously compounded attrition. See footnote 17 below for detalls of the correspondence between continuous and discrete time measures.

${ }^{3}$ A form of equation (7) which accounts for $\pi$ and $\gamma$ separately is

$$
\Delta u=\hat{\phi}-\left(\frac{\pi}{1+\gamma}-\frac{\bar{\pi}}{1+\bar{\gamma}}\right) u_{-1}-\left(\frac{\gamma}{1+\gamma}-\frac{\bar{\gamma}}{1+\bar{\gamma}}\right) u_{-1}+\left(\frac{\bar{\pi}+\bar{\gamma}}{1+\bar{\gamma}}\right)\left(\bar{u}-u_{-1}\right)
$$

This form will be used in the empirical work below. The negative sign of the $\left(\frac{\gamma}{1+\gamma}-\frac{\bar{\gamma}}{\overrightarrow{+}}\right) u_{-1}$ term appears puzzling because we naturally think of $\hat{\phi}$ increasting as $\hat{\gamma}$ increases. In a partial sense, however, the more of a given increase in search flow that comes from new entrants, the lower will be the unemployed relative to the labor force. In other words, a given increase in $\hat{\phi}$ causes a slightly smaller increase in $\Delta u$ if it comes about from new entrants as compared to the previously employed because in the former case the denominator of the unemployment rate 1 s increased as well as the numerator. This neglects any secondary effect on $\pi$ should new entrants have an expected search duration which differs from that of the previously employed. 


$$
\Delta u=\hat{\phi}-\hat{\pi}^{\star} u_{-1}+\bar{\pi} \star\left(\vec{u}-u_{-1}\right)
$$

That is, an abnormally high rate of new searchers, or an abnormally low probability of finding an acceptable job tends to increase the unemployment rate, but aside from these shocks the unemployment rate converges to its natural rate with a constant partial adjustment factor $\bar{\pi}^{\star} .4$

To illustrate the implications of equation (7), suppose for simplicity that an unexpected economic shock increases $\hat{\phi}$ and lowers $\pi^{*}$ temporarily until information on the change in policy can be incorporated in the expectations of entrepreneurs, searchers, and the public. Figure 1 illustrates the behavior of the unemployment rate on the assumption that these expectations effects on search flow and the instantaneous probability of employment last for one period only. The figure shows that a one-period expectations error implies a persistent effect on unemployment and hence on real output in the standard search-unemployment model. In the second period, the probability that each searcher finds a job is at the normal level, but the additional unemployment engendered in the first period takes time to work off. If we were to suppose that the inftial effect of a restrictive demand shock is in part to build up inventories and that these excessive inventories lead to $\phi>\bar{\phi}$ in successive periods, the interval in which unemployment rates rise would be prolonged.

It may seem strange at first that when workers realize that they made a mistake last period, $\pi *$ returns only to 1 ts normal value rather than going below $\bar{\pi}^{*}$ to compensate for the error. A bit of overshooting is possible if

4 The rate $\bar{\pi}^{*}$ is not necessarily constant over time. For example, in the empirical work we show that it varies with the demographic composition of the labor force. For our immediate purposes, however, we may assume that it is constant. 

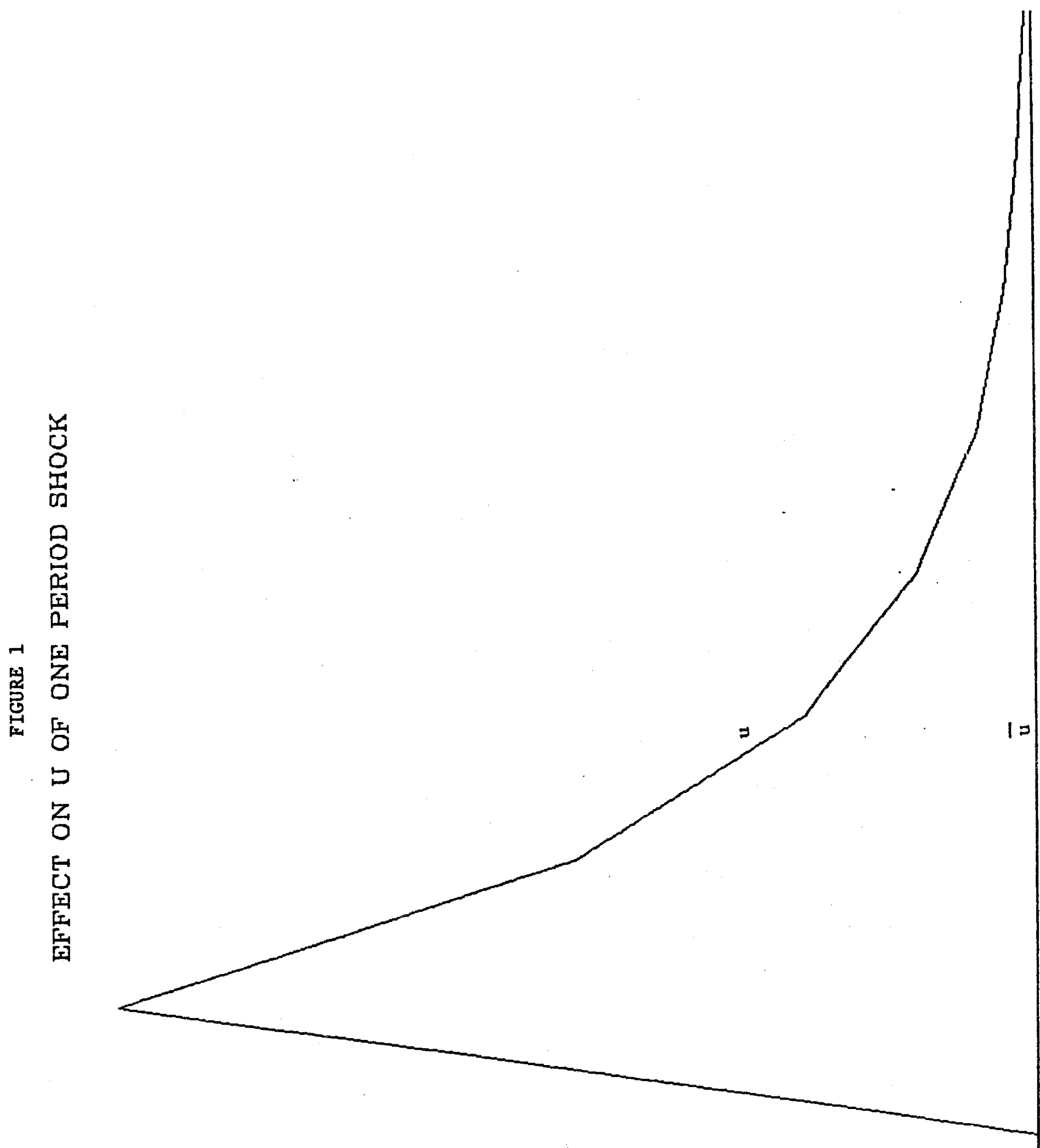

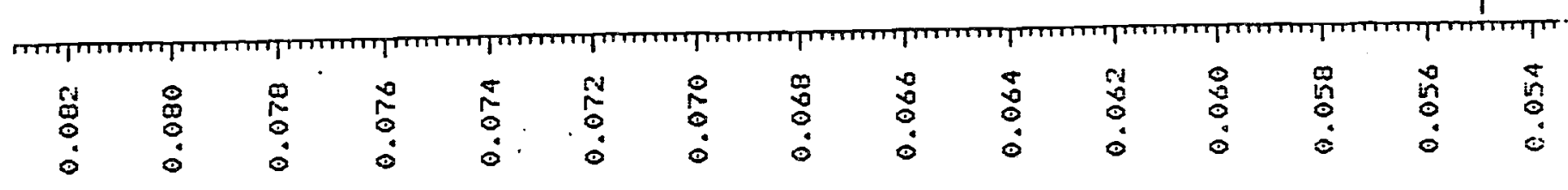


there are financing constraints, but generally past errors are forever bygones and optimal sequential search w111 imply a reservation wage which results in the normal probability of successful fob search. 5 This is not to deny that the wage offer distribution is likely to shift over the course of the cycle. In particular, one would expect the mean of the offer distribution to fall as the economy moves into a recession. However, as demonstrated by Lippman and McCall (1976, 1984), a correctly percelved decline in the mean of the offer distribution will, in general, imply a decline in reservation wages but the effect on the probability of receiving an acceptable offer ( $\pi$ ) will be ambiguous. 6

The stock of search unemployed workers can be 1ncreased from its equilibrium value by a single-period expectational error. Once this excess stock comes into existence a fraction is eliminated each period through successful search in the market place. Thus search dynamics alone imply persistent unemployment effect of one-time shocks in the economy. These effects are analogous to those previously discussed by equilibrium theorists

${ }^{5}$ See LIppman and McCall (1984). Simple sequential search models imply that the expected remaining duration of search is a constant $(1 / \bar{\pi})$ for uncompleted spells of unemployment when workers correctly percelve the potential distribution of offers. Financing constraints could be introduced to make the reservation wage a decreasing function of the length of unemployment experienced.

${ }^{6}$ It is worthwhile to remind the reader that the typical explanation of $\pi$ being procyclical involves incorrectly percelved shifts in the offer distribution. For correctly percelved shifts, however, the effect on $\pi$ is ambiguous as noted. It may be argued that the presence of positive or negative externalities associated with a change in the number of searchers (e.g., Diamond 1982 and Howitt 1985) should play a role here. But these factors will involve a change in the shape (or a shift) in the offer distribution. Following the above arguments, if the change in the offer distribution is correctly percelved, then reservation wages are likely to change but any change in the probability of accepting an offer is likely to be second order in magnitude. 
for inventories, Investment projects in process, and other such state variables. The persistent unemployment and output effects are not due to any persistent errors on the part of workers or firms, but instead due to the dynamic process of search in the labor market. In Sections III and IV below, we present empirical evidence that the interaction of inventory and unemployment dynamics does produce a hump-shaped time path of the unemployment rate in response to brief unexpected shocks.

\section{I.B. Heterogeneous Workers}

A second element of employment dynamics which plays an important role in explaining the persistence of unemployment subsequent to a macroeconomic shock is the heterogeneous nature of workers. As a general proposition, it has become increasingly accepted that heterogeneity across workers is important for understanding the behavior of unemployment. Realization that workers in different submarkets (e.g., demographic, Industrial, occupational) may exhibit different turnover behavior has led to a recognition that the natural rate of unemployment will vary with the composition of the labor market (see for example, Wachter 1976, Lilien 1982, and Haltiwanger and Plant 1984). 7 Heterogeneity has also played an important role in the study of the distribution of unemployment duration. Specifically, the presence of heterogeneity implies a bias in using the observed (from the BLS household survey) uncompleted spell distribution to measure the unobserved completed spell distribution (see, for example, Salant 1976 and Akerlof and Main 1980). Thus, we are clearly not the first to identify heterogeneity as an important factor for understanding

7 We incorporate this idea into our measure of the natural rate of anemployment in Section II. 
the labor market. Rather our innovation is to examine the ramifications of heterogeneity for persistence in unemployment over the business cycle. In particular, in this section we demonstrate theoretically how heterogeneity is potentially a source of persistence over the cycle and then in succeeding sections we provide empirical evidence that indicates that heterogeneity is a major factor underlying the observed persistence in $\pi$ (and hence in $u$ ). For simplicity, we can think of workers as being divided into two groups. Those in the first group have little firm-specific human capital and they experlence unemployment frequently, but the length of these spe11s are brief. Thus, $\phi_{1}$ and $\pi_{1}^{*}$ are large since there is little to be gained from extensIve search for short-term employment. Members of the second group rarely experience unemployment, but when it occurs, search is extensive and well supported by unemployment compensation, other family income, and assets. So $\phi_{2}$ and $\pi_{2}^{*}$ are both low. ${ }^{8}$ The normal unemployment rate is

$$
\bar{u}=\frac{n_{1}}{n} \bar{u}_{1}+\frac{n_{2}}{n} \bar{u}_{2}=\frac{n_{1}}{n} \frac{\bar{\phi}_{1}}{\bar{\pi}_{1}}+\frac{n_{2}}{n} \frac{\bar{\phi}_{2}}{\bar{\pi}_{2}} .
$$

We cannot observe Individual values of the $\pi_{1}$ 's and $\phi_{1}$ 's, but only their appropriately weighted averages. Of particular interest is $\pi$ :

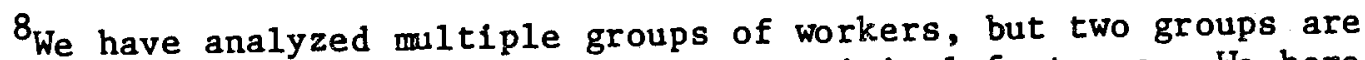
sufficlent to capture the most important empirical features. We here explain the tendency, ceteris paribus, for $\pi$ to decline as duration of unemployment increases by the sorting hypothesis: The expected duration of unemployment varies inversely with $\pi$ so that low $\pi$ individuals comprise a larger share of longer duration relative to short duration unemployment. See Heckman and Borjas (1980) and Carlson and Horrigan (1983). Alternatively, $\pi$ might itself decrease as duration increased. As discussed below, we believe that the data are best explained by the sorting hypothesis. 


$$
\pi=\sum \frac{s_{1,-1}}{s_{-1}} \pi_{1}=\pi_{2}+\left(s_{1,-1} / s_{-1}\right)\left(\pi_{1}-\pi_{2}\right)
$$

This overall average probability of leaving unemployment can change either because of changes in the individual $\pi_{1}^{\prime}$ s or because of changes in the unemployment shares $\left(s_{1} / s\right)$ :

$$
\Delta \pi=\sum_{1} \frac{s_{1,-2}}{s_{-2}} \Delta \pi_{1}+\sum_{1} \pi_{1} \Delta\left(\frac{s_{1,-1}}{s_{-1}}\right)
$$

Consider once again a one period shock. To concentrate on issues of persistence, suppose that people always search optimally $\left(\pi_{1}=\bar{\pi}_{1}\right.$ always but that a one-period increase in the $\phi_{1}^{\prime} s$ results in the same proportionate increase in each $s_{1}$. In the two group case, $s_{2} / s=1-\left(s_{1} / s\right)$. Holding $\pi_{1}$ and $\pi_{2}$ constant, we have from equation $(10)$ :

$$
\Delta \pi=\left(\bar{\pi}_{1}-\bar{\pi}_{2}\right) \Delta\left(s_{1,-1} / s_{-1}\right)
$$

For the first two periods, by assumption, lagged $s_{1} / s$ is unchanged so the observed $\pi$ remains constant at $\bar{\pi}$. For each group unemployment rates will follow a pattern like that exhibited in Figure 1 , but reflecting the $\bar{\pi}_{1}$ appropriate to the group. In Figure 2 we plot the number of persons unemployed In each group, $s_{1}$, which is simply the product of the group unemployment rate and the size of the group $\left(s_{1}=u_{1} n_{1}\right) .9$ Once the search flows return to normal, the excess unemployment is eliminated in each group at the rate $\bar{\pi}_{1}$. At time 2, the lagged values of $s_{1}$ and $s_{2}$ have increased by the same pro-

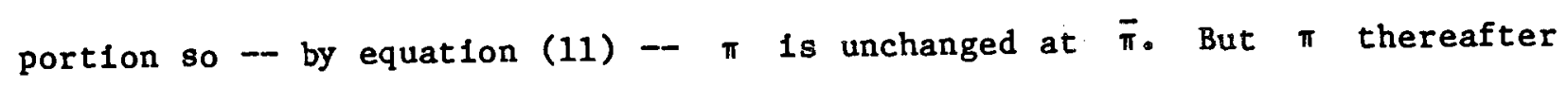

${ }^{9}$ Since we have neglected the growth in the labor force, the transformation from $u$ to $s$ only shifts the relative positions of $u_{1}$ and $u_{2}$ so that they can be added together to obtain $u=\frac{n_{1}}{n} u_{1}+\frac{n_{2}}{n} u_{2}$. 


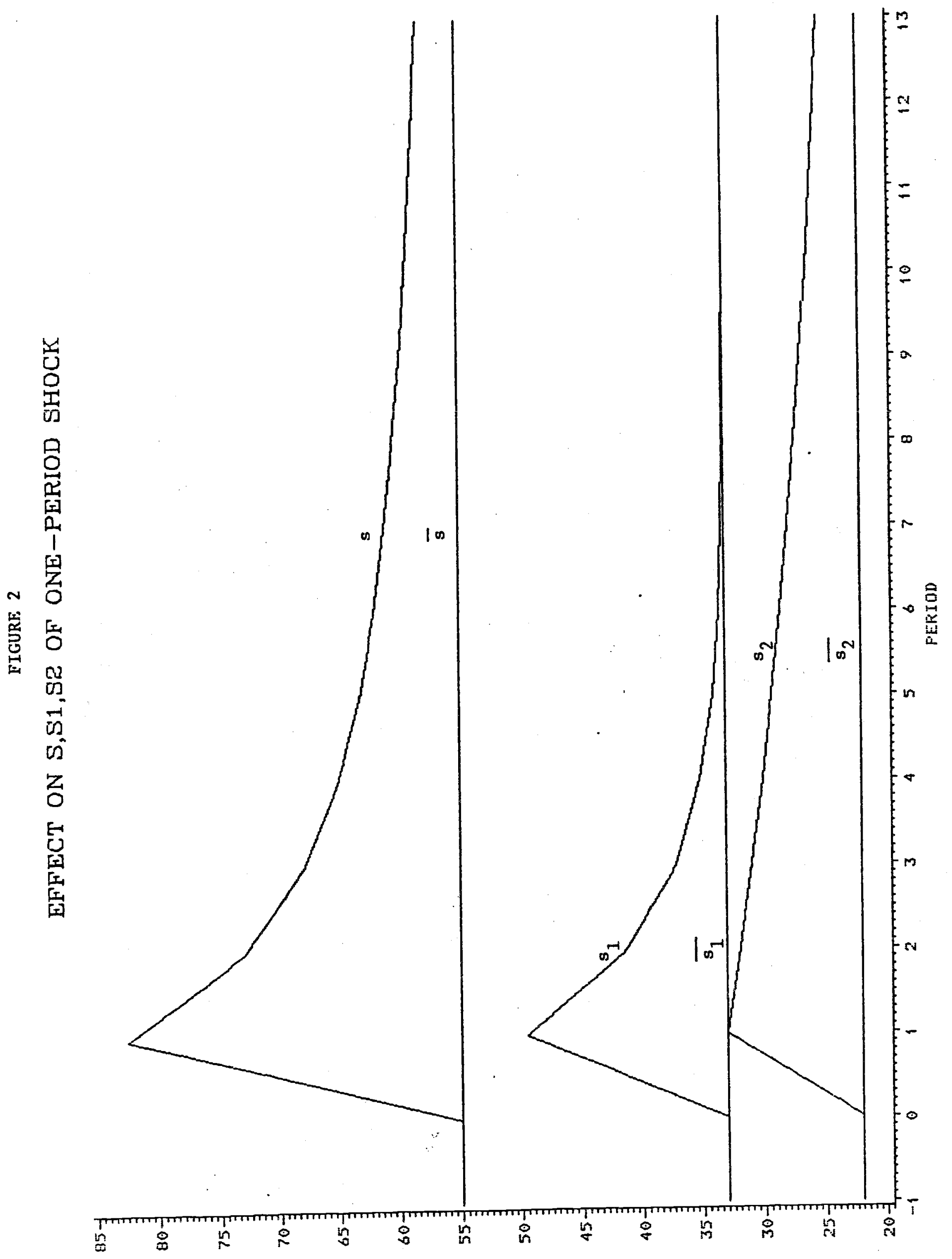


begins to decline for a number of periods as the share $s_{1} / s$ drops. This happens because $\pi_{1}>\pi_{2}$ so $s_{1}$ returns to normal much faster than does $s_{2}$. However (after about period 6 in the figure), nearly all the adjustment in group 1 is completed so that the decreases in $s_{2}$ are proportionately larger. Thereafter, $s_{1} / s$ and hence $\pi$ rise back toward their normal levels.

In conclusion, the slower adjustment of the lower probability group will appear in the aggregate data as a persistent $\hat{\pi}$ even though each individual worker is searching optimally with $\pi_{1}=\bar{\pi}_{1}$. The problem arises because $\bar{\pi}$ is based on the normal distribution of unemployment among groups:

$$
\bar{\pi}=\frac{n_{1} \bar{u}_{1}}{n \bar{u}} \bar{\pi}_{1}+\frac{n_{2} \bar{u}_{2}}{n \bar{u}} \bar{\pi}_{2}
$$

After a recession causes mass disemployment, the low probability group will be overrepresented for a considerable perlod of time. During the recovery period (with $\phi_{1}=\bar{\phi}_{1}, \phi_{2}=\bar{\phi}_{2}$, and $\gamma_{1}=\gamma_{2}=\bar{\gamma}$ ), $u_{1}$ quick1y returns to $\bar{u}_{1}$ and thereafter we observe

$$
\Delta u=\pi_{2}^{*}\left(\vec{u}-u_{-1}\right)
$$

Were $\bar{\pi}_{2}$ sufficiently low, the return to the normal unemployment rate could be painfuliy slow in the absence of a later stimulative monetary or fiscal shock. 10 Note also that during this long recovery period the share of group 2

${ }^{10}$ This model would appear to provide a new basis for Axel Leijonhufvud's corridor notion (1981) in which the economy converges to long-run equilibrium abnormaliy slowly after a major perturbation. Note, however, that it is hard to belleve that exceedingly low values for $\bar{\pi}_{2}$ could be socially optimal even if they were privately optimal given our system of transfer payments. It is not clear -- of course - that stimulative monetary or fiscal policy has the same power to reemploy group 2 workers as it does to disemploy them through bankruptcies and permanent layoffs. 
unemployed w111 be abnormally large which 1mplies, from equation (9) that $\pi$ w11l be abnormally low $(\hat{\pi}<0)$. As a result an analyst looking at only the aggregate equation (7) might incorrectly conclude that convergence to the natural unemployment rate $\bar{u}$ would be much faster were persistent expectational errors not keeping $\hat{\pi}$ negative. But we are considering a case in which each Individual always correctly percelves the wage distribution so that $\pi_{1}=\bar{\pi}_{1}$ always. So persistence in aggregate $\hat{\pi}$ may reflect expectational error or significant heterogeneity in $\pi$ across individuals. 11

This discussion of heterogeneity suggests that considerable care must be taken in defining the natural rate of unemployment. Movements in the unemployment rate w111 be highly correlated with changes in the composition of the pool of unemployed workers. So any measure of the natural rate that uses weighted averages of normal levels of $\pi_{1}$ and $\phi_{1}$ where weights are unemployment shares (for example, $\bar{\phi} / \Sigma \frac{s_{1}}{s} \bar{\pi}_{1}$ ) will result in most movements in $u$ being explained by movements in the natural rate. ${ }^{12}$ Adjustment to normal levels of unemployment is reflected in adjustments in the share of unemployment among groups, and thus variations in shares should not be used to capture variation in the natural rate of unemployment.

$11_{\text {Recall that }}$ in the case just considered the accounting identity (7) w11l continue to hold although equation (13) is governing the convergence to the natural rate.

${ }^{12}$ Some hard-won lessons in this regard are imparted in Section III below. 


\section{Measurement}

In the previous section, we demonstrated that the determinants of search rate $\phi$, the employment probability $\pi$, and the labor-force growth rate $\gamma$ were Important in the analysis of the cyclical pattern of unemployment and real output. In this section we first consider the measurement of $\phi$, $\pi$, and $\gamma$, then decompose the measured values into cyclical and normal components, and finally obtain a measure of the heterogenelty of $\pi$ across individuals. At present, we are not able to measure (separately) values of $\phi$ and $\pi$ for those on temporary layoffs and those who are searchers (a11 others). ${ }^{13}$ We postpone the development of such measures to future research.

II.A. The Measurement of $\phi, \pi$, and $\gamma$. Since the size of the labor force is a regularly reported statistic, we have no difficulty in computing $\gamma$, the growth rate of the labor force. To measure $\phi$ and $\pi$ we would 1deally like to have data that reports the gross flows of the number of workers among three states: employed, unemployed, and not in the labor force. Unfortunately complete data of this sort are not regularly and reliably collected. 14 However, we can obtain very good estimates of $\pi$ and $\phi$ from the avallable data on the aggregate number, $s$, unemployed each month and the number, $s^{0-4}$, who have been unemployed "0-4 weeks."

${ }^{13}$ If we could, we would like to measure $\phi_{L}$ as the fraction of the labor force beginning temporary layoff within the month and $\pi_{L}$ as the probability of being recalled from temporary layoff within the month.

14 For a discussion of the avallability of and problems with the gross flow labor force data, see Smith and Vanski (1979). 
Recall that the Current Population Survey is conducted each month during the week which contains the 12th day of the month. Thus the typical year has twelve surveys of which 8 are conducted 4 weeks subsequent to the previous survey and 4 are 5 weeks subsequent to the previous survey. We find 1 t convenient to use standard months of 4.35 weeks $(30.4$ days $=365 / 12)$. Since $\mathrm{s}^{0-4}$ reports the number of people unemployed 31 days or less, it is a good measure of the people who have become unemployed over the last month. 15 The number unemployed at the last survey is used to approximate $s_{-1}$, the number unemployed exactly one month earlier. The equivalence is exact whenever $u_{-1}$ equals the value $\phi \frac{1+\gamma}{\pi+\gamma}$ toward which the unemployment rate currently converges as 1t would, for example, In steady-state equilibrium; otherwise the error introduced in estimating $\pi$ is bounded by 0.02 for plausible values of the relevant parameters. 16 These data are sufficient to calculate $\pi$ as

$$
\pi=1-\frac{s-s^{0-4}}{s-1}
$$

since $1-\pi$ is the fraction of individuals unemployed last month who are still unemployed.

Our measured $\pi$ tells us how much longer the average currently unemployed person would be unemployed under current conditions: $(1 / \pi)$ months. This would be the expected total duration of the average newly unemployed person only if the ratio of search flows, $f_{1} / f_{2}$, equals the ratio of the unemployment shares, $s_{1} / s_{2}$. In steady-state equilibrium, for example,

${ }^{15}$ Census enumerators, who have a calendar before them during an interview, round unemployment duration to the nearest whole number of weeks. Correction for the difference between 30.4 and 31 days 1 s not attempted.

${ }^{16}$ Since $\pi$ normally lies between 0.4 and 0.6 , this is an acceptable margin of error. See Appendix A for detalls. 
$f_{1} / f_{2}$ exceeds $s_{1} / s_{2}$ so that the average expected duration of newly begun unemployment is less than the average expected remaining duration of the currently unemployed.

The corresponding measure of $\phi$ is

$$
\phi=s^{0-4} / n
$$

where $n$ is the civilian labor force. Note that this discrete time measure of $\phi$ measures the flow of people who become unemployed between monthly observations and are still unemployed at this monthly observation. The continuous-time search rate would be higher. 17

Monthly values of our estimates of $\phi$ and $\pi$ are avallable from the authors on request. Figure 3 plots quarterly averages of the monthly values of $\pi$. The mean value of 0.46 is interpreted as saying that on average 46 percent of the people who are unemployed at the beginning of a month w111 find a job, leave the labor force, or be recalled from layoff by the end of the month. The vertical lines mark cyclical peaks $(P)$ and troughs $(T)$ on the

${ }^{17}$ Let $\psi$ be the continuous time search rate, $\theta$ be the Poisson parameter such that the probability of finding a fob between $t$ and $t+d t$ is Qdt, and $\bar{\gamma}$ be continuously compounded monthly growth rate of $n$. Then the observed value of $\phi$ is given by

$$
\phi=\left(\int_{0}^{1} n_{1} e^{\bar{\gamma}(1-t)} \psi e^{-\theta t} d t\right) / n=\psi\left(1-e^{-\theta-\bar{\gamma}}\right) /(\theta+\bar{\gamma}) \text {. }
$$

Note that the observed value of $\pi$ is simply $1-e^{-\theta}$. Taking $\bar{\gamma}=0$, the following correspondence are observed:

$\begin{array}{llc}\frac{\pi}{0.2} & \frac{\theta}{.223} & \phi / \psi=\pi / \theta \\ 0.3 & .357 & .896 \\ 0.4 & .511 & .841 \\ 0.5 & .693 & .783 \\ 0.6 & .916 & .721 \\ 0 & & .655\end{array}$

Thus the observed monthly probability of finding a job $\pi$ is less than its continuous time equivalent $\theta$, and the observed monthly flow into unemployment $\phi$ is less than the continuous time equivalent $\psi$. 
18

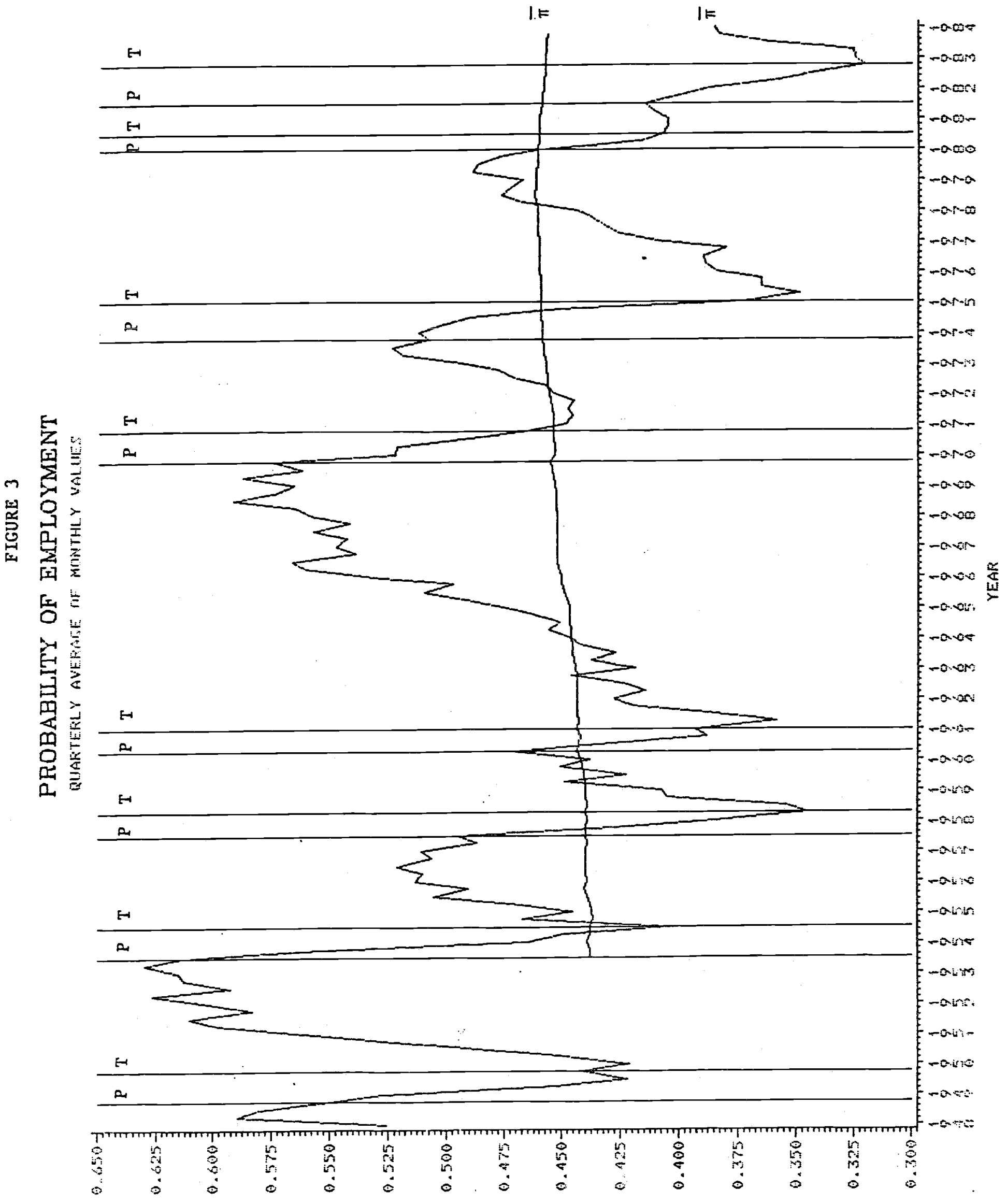


NBER reference cycle chronology. We note first that the values of $\pi$ tended to be rather higher (around 0.6) during the Korean and Vietnamese eras and also that the monthly probability of getting a fob drops sharply during a recession and rises in a boom. Our estimate of $\bar{\pi}$ is derived and discussed in Section II.B below.

Figure 4 similarly plots quarterly averages of monthly values of $\phi$. We see that $\phi$ generally follows an upward trend although 1 t 1 s sharply below trend in both the Korean and Vietnamese eras. The cyclical behavior is sharply contracyclical -- rising in recessions and falling in booms.

\section{II.B. Cyclical and Normal Components}

In equations (6) and (7) we analyze unemployment rate dynamics in terms of normal values $\bar{\phi}, \bar{\pi}, \bar{\gamma}$, and $\vec{u}$ and the corresponding cyclical components $\hat{\phi}, \hat{\pi}, \hat{\gamma}$, and $\hat{u}$. In this section we develop estimates of these quantities. Following Barro $(1977,1978)$ and Wachter $(1976)$ we develop measures of $\bar{\pi}, \bar{\phi}$, and $\bar{\gamma}$ which reflect the effects of the military draft and the age-sex composition of the labor force on the natural rate of unemployment and derive a measure of $\bar{u} \cdot 18$

We define $\bar{\pi}$ by

${ }^{18}$ It might be useful to examine the effect of the industrial or occupational composition of the labor market on $\bar{\pi}, \bar{\phi}$, and $\bar{\gamma}$. This is of interest because the recent work of Lilien (1982) suggests that the industrial composition is important for measuring the overall natural rate of unemployment. However, to incorporate these ideas in this context, unemployment duration data broken down simultaneously by age, sex, industry and occupation would be required and such a four way classification of this data is not avallable. Confronted with the cholce of which decomposition matters most, we chose the age-sex classification. This is because the age-sex breakdown of the unemployment duration data is relatively more avallable and previous studies (e.g., Wachter 1976, Haltiwanger and Plant 1984) have demonstrated that the age-sex composition of the labor force is very important. 


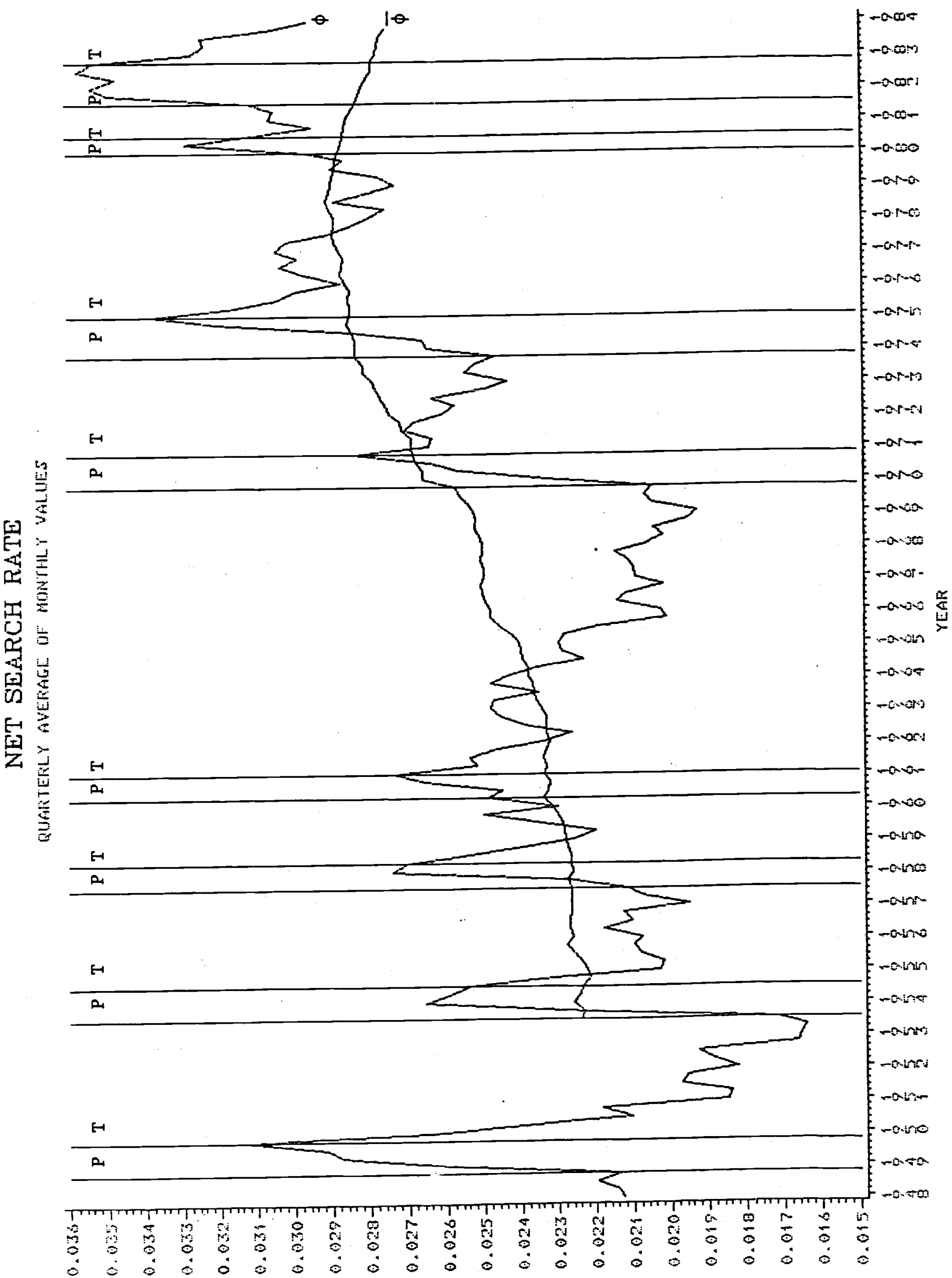




$$
\bar{\pi}=\sum \frac{n_{1,-1} \bar{u}_{1,-1}}{1 \sum_{j} n_{j,-1} \bar{u}_{j,-1}} \bar{\pi}_{1}
$$

where the summations are over age-sex cells. ${ }^{19}$ Labor force shares and unemployment rates by age and sex are avallable monthly but the number who have becone unemployed during the last month by age and sex is only avallable as an annual monthly average beginning in 1967.

For all age and sex groups other than males 16-19 and males 20-24 we hypothesize that $\bar{\pi}_{1}$ is constant over time. This allows us to use the avallable data to measure $\bar{\pi}_{1}$ with the following steady-state version of equation (14) for group 1 where $A()$ denotes annual averages: 20

$$
\bar{\pi}_{1}=1-\operatorname{mean}\left[\frac{A\left(s_{1}\right)-A\left(s_{1}^{0-4}\right)}{A\left(s_{1,-1}\right)}\right]
$$

For males 16-19 and 20-24 the normal $\bar{\pi}_{1}$ is allowed to vary over time with the nature of the military draft. To measure $\vec{\pi}_{1}$ for these two young male groups we estimate the following equation: 21

$$
A\left(\pi_{i}\right)=\alpha_{0}+\alpha_{1} A(\text { MIL })+\alpha_{2} A\left(\pi_{j}-\bar{\pi}_{j}\right)+\alpha_{3} A\left(\pi_{k}-\bar{\pi}_{k}\right)
$$

19 We must be careful to use normal unemployment welghts in formula (16) since we have seen that after a recession causes mass disemployment low probabllity groups -- predominant among prime-age males -- will be overrepresented for some time. Therefore the use of actual unemployment weights will lead to spurious procyclical movements in measured $\vec{\pi}$ and hence contracyclical movements in $\vec{u}$. Thls type of problem seems to be at the root of other estimates of $\vec{u}$ which fluctuate sharply with the business cycle.

${ }^{20} \mathrm{All}$ measures of normal $\bar{\pi}, \bar{\phi}, \bar{\gamma}$ and $\vec{u}$ are based on data from 19671983. $A\left(s_{1,-1}\right)$ denotes the annual average of data from the prior December through November of the current year, and the mean is taken over the perlod 1967-83.

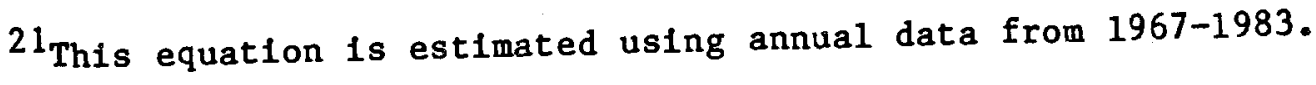


where $\pi_{1}$ refers to elther males $16-19$ or 20-24, MIL is Robert Barro's military draft variable, and $\pi_{j}-\bar{\pi}_{j}$ and $\pi_{k}-\bar{\pi}_{k}$ are the deviations from the mean of the annual average of monthly $\pi_{j}$ and $\pi_{k}$ for males 35-44 and 45-54 respectively. 22 The latter two varlables are included to account for cyclical variation in $\pi_{1}$. Using the estimated coefficients from this equation, $\bar{\pi}_{1}$ for males $16-19$ and $20-24$ is calculated as:

$$
\bar{\pi}_{1}=\hat{\alpha}_{0}+\hat{\alpha}_{1} \text { MIL }
$$

We define $\bar{\phi}$ as:

$$
\bar{\phi}=\sum_{1} \frac{n_{1}}{n} \bar{\phi}_{1}
$$

where the summations are over age-sex cells.

Similar to our measurement of $\bar{\pi}_{1}$, the normal $\bar{\phi}_{1}$ for group 1 for agesex groups other than males $16-19$ and 20-24 1s measured by the 1967-83 mean of equation (14) for group 1:

$$
\bar{\phi}_{1}=\operatorname{mean}\left(\frac{A\left(s_{1}^{0-4}\right)}{A\left(n_{1}\right)}\right)
$$

For males 16-19 and 20-24 $\bar{\phi}_{1}$ is measured using an adjustment for the effect of the military draft similar to that used to adjust $\bar{\pi}_{1}$ for the military draft.

$$
\text { We define } \bar{\gamma} \text { as: }
$$

22 The milltary variable is zero in the years in which there was no draft (January 1970 to December 1983), and equal to the ratio of the number of military personnel to the male population age 16 to 34 in years in which a draft was present. The draft after 1970 was a lottery draft. Following Barro (1977, 1978), we include this in the "non-draft" period since the incentives to search were considerably decreased by this process of conscription. Monthly data for this variable is ava1lable beginning 1953-58. 


$$
\bar{\gamma}=\sum_{1} \frac{n_{1}}{n} \bar{\gamma}_{1}
$$

where the summations are over age-sex cells and $\bar{\gamma}_{1}$ is measured as the mean of the observed monthly growth rates for group 1 .

Having measured $\bar{\pi}_{1}, \bar{\phi}_{1}$, and $\bar{\gamma}_{1}$ for each group 1 , we can measure $\bar{u}_{1}$ by an age-sex specific version of equation (6). The aggregate values $\bar{\pi}$ and $\bar{\phi}$ are obtalned from equations (16) and (20) and used with $\bar{\gamma}$ and equation (6) to obtain the aggregate normal unemployment rate $\bar{u}$ which rises (see Figure 5) until the late 1970 s and then begins to drift downward.

Examining Figures 3 and 4 , we see that $\bar{\pi}$ is relatively constant and the key factor moving $\bar{u}$ is $\bar{\phi}$ which indeed increases during the 1970s and then falls off somewhat in the early 1980s. This can be explained by examining the estimates of the $\bar{\pi}_{1}$ and $\bar{\phi}_{1}$ values.

Table 1 reports the estimated normal values for $\bar{\pi}_{1}, \bar{\phi}_{1}, \bar{\gamma}_{1}$, and $\bar{u}_{1}$ by age and sex. 23 During the 1970 s the labor force share of the young 1ncreased and then decreased slightly in the early 1980 s as the baby boom generation grew older. Since, as reported in Table 1, the young have relatively high probabilities of leaving unemployment, this accounts for the small movements In $\bar{\pi}$ over this period.

F1gure 4 includes a plot of the quarterly averages of monthly values of $\bar{\phi}$. We see that $\bar{\phi}$ follows a general upward trend that is dramatic in the early to mid-1970s but falls off in the early 1980s. Since the $\bar{\phi}_{1}^{\prime}$ s are

${ }^{23}$ In a recent study of micro turnover data, Robert Topel (1984) found results similar to those reported here. Namely, that as age and experience in the work force increased, the likelthood of becoming unemployed $(\phi)$ decreased but the likelihood of leaving unemployment ( $\pi$ ) decreased as well. 


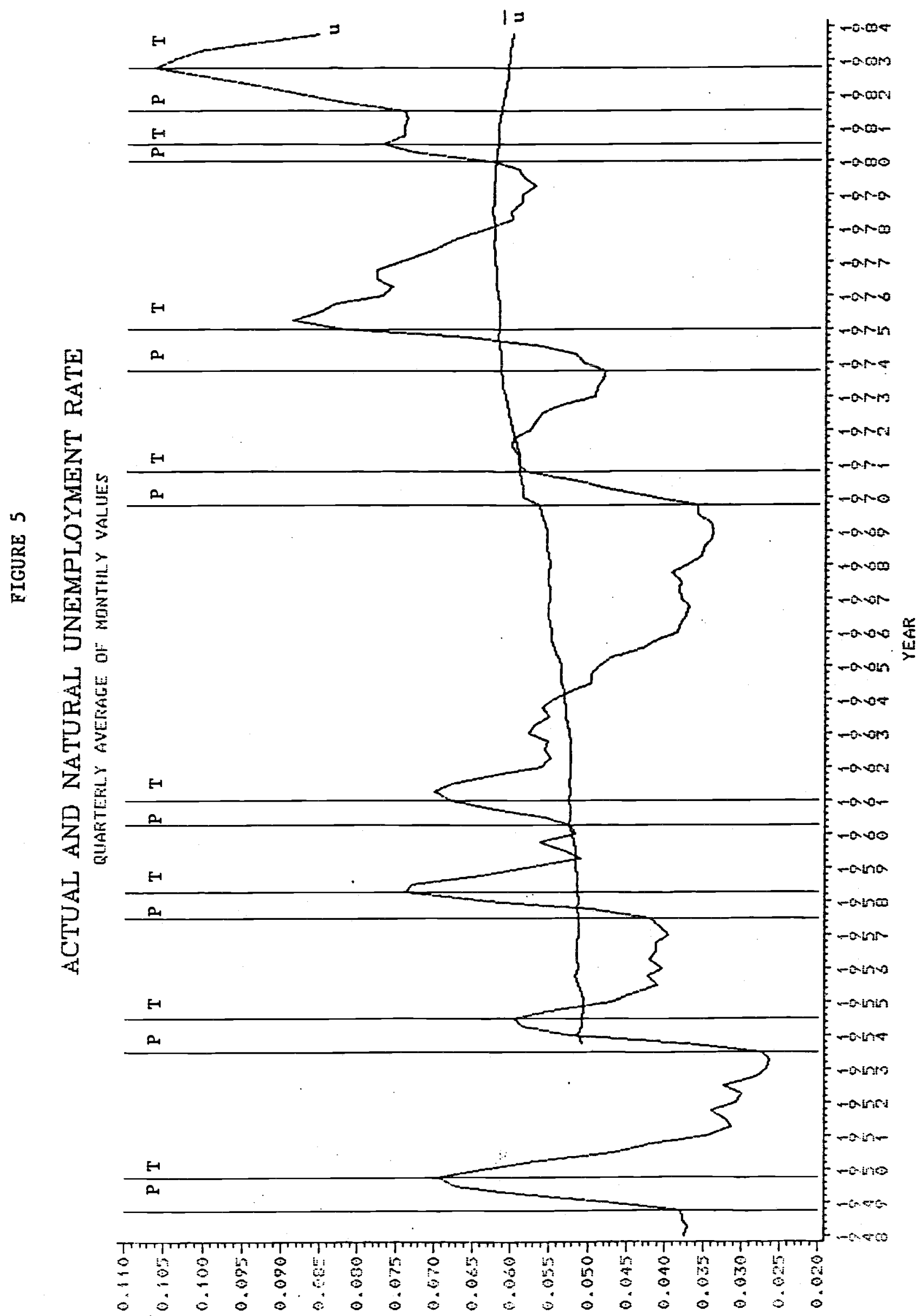


TABLE 1

Estimated Normal Values of $\pi$ and $\phi$ by Age and Sex

\begin{tabular}{|c|c|c|c|c|c|c|c|c|}
\hline \multirow[t]{2}{*}{ Age Group } & \multicolumn{4}{|c|}{ Males } & \multicolumn{4}{|c|}{ Females } \\
\hline & $\bar{\gamma}_{1}$ & $\bar{\pi}_{1}$ & $\bar{\phi}_{1}$ & $\vec{u}_{1}$ & $\bar{\gamma}_{1}$ & $\vec{\pi}_{1}$ & $\bar{\phi}_{1}$ & $\bar{u}_{1}$ \\
\hline $16-19$ years $^{a}$ & 0.0023 & 0.5366 & 0.0895 & 0.1665 & 0.0028 & 0.5715 & 0.0974 & 0.1701 \\
\hline $20-24$ years $^{a}$ & 0.0036 & 0.4373 & 0.0434 & 0.0988 & 0.0043 & 0.5243 & 0.0506 & 0.0964 \\
\hline $25-34$ years & 0.0033 & 0.3847 & 0.0179 & 0.0463 & 0.0060 & 0.4932 & 0.0333 & 0.0671 \\
\hline $35-44$ years & 0.0005 & 0.3571 & 0.0114 & 0.0319 & 0.0024 & 0.4584 & 0.0229 & 0.0498 \\
\hline $45-54$ years & -0.0002 & 0.3379 & 0.0102 & 0.0301 & 0.0012 & 0.4262 & 0.0172 & 0.0403 \\
\hline $55-64$ years & 0.0003 & 0.3164 & 0.0101 & 0.0320 & 0.0015 & 0.3966 & 0.0136 & 0.0342 \\
\hline $\begin{array}{l}65 \text { years and } \\
\text { over }\end{array}$ & -0.0004 & 0.3449 & 0.0122 & 0.0355 & 0.0016 & 0.3888 & 0.0133 & 0.0342 \\
\hline
\end{tabular}

Calculated as described in text.

a Reported values of $\bar{\pi}_{1}$ and $\bar{\phi}_{1}$ for young males (16-24) are the values since 1970:1 with MIL $=0$. Prior to 1970:1, these values varied monthly with the draft varlable MIL. 
relatively constant over time, equation (20) indicates that this variation in $\bar{\phi}$ must be the result of variation in labor force shares. Our examination of the labor force share data reveals that the upswing in $\bar{\phi}$ in the early to middle 1970s is accounted for by the influx of the young and women into the labor force; both are relatively high turnover groups as evidenced by Table 1. Accordingly, the falloff in $\bar{\phi}$ in the early 1980s is accounted for by the decreased share of the young in the labor force as the baby boom generation grew older. The estimated $\bar{\phi}$ values move more dramatically than $\bar{\pi}$ because of the much greater variation in $\phi_{1}$ than in $\pi_{1}$ values.

\section{II.C Evidence of Heterogeneity in $\pi$}

The adjustment of the aggregate measure of $\pi$ to its equilibrium value, $\bar{\pi}$, can be slowed by the presence of heterogenelty in the labor market. As we showed in Section I.B, if there are two groups with different values of $\bar{\pi}_{i}$ and $\bar{\phi}_{1}$, aggregate measures of $\pi$ can show persistent deviations from $\bar{\pi}$, even though within groups there is no persistent deviation from equilibrium values. Any attempt then to measure persistence in $\hat{\pi}$, and thus $\hat{u}$, requires an empirical characterization of heterogeneity. In this section we provide empirical evidence of heterogeneity in $\pi$.

Let $d_{v}$ denote the average duration of unemployment this month for those who were unemployed last month and are st11l unemployed, and let $d_{-1}$ denote the average duration of unemployment in the previous month for all unemployed workers. Suppose that all individuals have the same probability of exiting unemployment, $\pi$; that is, there is no heterogeneity. Then:

$$
d_{v}=d_{-1}+1
$$

Given a uniform escape probability at any point in time, the average duration of unemployment for those remaining unemployed in a given month should 
increase by one month. However, if individuals are heterogeneous, and thus have different values of $\pi$, then $d_{v}$ will generally exceed $d_{-1}+1$ because a disproportionate share of high duration (1ow $\pi$ ) workers remain unemployed at the end of a month's time.

Given a heterogeneous workforce, on average $d_{v}$ will exceed $\left(d_{-1}+1\right)$ by some positive value, call it h. Thus,

$$
d_{v}=d_{-1}+1+h
$$

Let $d_{n}$ denote the average duration of people who became unemployed in the last month. Then the average duration of unemployment in a given month, $d$, is simply a weighted average of $d_{v}$ and $d_{n}$ :

$$
d=\frac{s-s^{0-4}}{s}\left(d_{-1}+1+h\right)+\frac{s^{0-4}}{s} d_{n}
$$

Solving (25) for $h$ yields:

$$
h=\frac{d-d_{n}\left(s^{0-4} / s\right)}{1-\left(s^{0-4} / s\right)}-d_{-1}-1
$$

Data on all of the right hand side variables are readily avallable, except for $d_{n}$ which can be approximated and in our sample lies between 0.4267 and 0.4691 .24 To compute the mean value of $h$ over 1953:8 through 1983:12, we

${ }^{24}$ Those who became unemployed within the month will have an average duration of less than one half month because those who became unemployed earlier in the month are more likely to have found a fob than the more recently unemployed. Assuming the Poisson distribution of note 17 above and $\bar{\gamma}=0$, the average duration of those who became unemployed within the month is

$$
d_{n}=\frac{\int_{0}^{1} t e^{-\theta t} d t}{\int_{0}^{1} e^{-\theta t} d t}=\frac{1-e^{-\theta}-\theta e^{-\theta}}{\theta\left(1-e^{-\theta}\right)}=\frac{1}{\theta}-\frac{e^{-\theta}}{1-e^{-\theta}}
$$


assume $d_{n}$ to be constant at 0.4495 which corresponds to the mean value of $\pi$ of 0.45674 . The resulting mean value, $\bar{h}$, is 0.973 . What does this value imply about the extent of heterogenelty in the labor force?

Suppose that the labor force can be characterized as consisting of two groups as in Section I.B. It is straightforward to determine the steady-state value of $\overline{\mathrm{h}}$ for alternative values of $\bar{\pi}_{1}$ and $\bar{\pi}_{2}$ given that the steadystate ratio of inflows $\overline{f_{1} / f_{2}}$ adjusts so that the aggregate $\bar{\pi}$ is equal to its sample mean of about 0.46 .25 Candidate pairs of values of $\bar{\pi}_{1}$ and $\bar{\pi}_{2}$ are those for which the calculated value of $\bar{h}$ is close to 0.973. Table 2 reports these pairs together with the implied values of $\overline{f_{1} / f_{2}}$ and $\bar{h}$. Note that the $\bar{h}$ in our sample implies two groups with substantially different values of $\bar{\pi}_{1}$.

We can get some idea of potential values for $\bar{\pi}_{1}$ and $\bar{\pi}_{2}$ from the range of values reported in Table 1 for broad age-sex cells. These values range from 0.31 to 0.57 . Suppose that the average $\bar{\pi}_{1}$ for $16-19$ year olds of both sexes - 0.55 - reflects $\bar{\pi}_{1}$, because these youngsters have not yet formed any permanent job attachments nor acquired specific human capital. 26 Table 2 tells us that $\vec{\pi}_{2}$ would be about 0.112 . If the normal unemployment rate among group 2 were about half the overall rate - say 2.75 percent - then $\bar{\phi}_{2}$ would be 0.00308 . Put differently the average duration of these

(fn. 24 cont.)--Recall that $\theta=-\log (1-\pi)$. The minimum and maximum values of $\pi$ observed over 1953:8 - 1983:12 are 0.31 and 0.59 for which the corresponding $d_{n}$ values are 0.4691 and 0.4267 , respectively.

${ }^{25}$ See Appendix B for detalls.

$26_{\text {The correct }} \bar{\pi}_{1}$ could be even a bit lower than this if the average high-probability individual has a lower probability than these youngsters of getting a job. or leaving the labor force. 
TABLE 2

$$
\begin{aligned}
& \bar{\pi}_{1}, \bar{\pi}_{2}, \text { and } \overline{f_{1} / f_{2}} \text { Combinations for Which } \\
& \bar{\pi}=0.45674 \text { and } h=0.973 \text { in Stationary-State Equilibrium }
\end{aligned}
$$

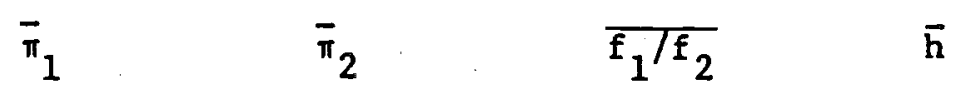

\begin{tabular}{llcl}
\hline 0.90 & 0.225 & 4.72 & 0.977 \\
0.85 & 0.217 & 4.72 & 0.976 \\
0.80 & 0.208 & 5.01 & 0.973 \\
0.75 & 0.197 & 5.60 & 0.973 \\
0.70 & 0.183 & 6.70 & 0.976 \\
0.65 & 0.166 & 8.70 & 0.974 \\
0.60 & 0.143 & 13.00 & 0.976 \\
0.55 & 0.112 & 24.85 & 0.968 \\
0.54 & 0.104 & 29.96 & 0.969 \\
0.53 & 0.095 & 37.35 & 0.975 \\
0.52 & 0.086 & 47.83 & 0.971 \\
0.51 & 0.076 & 64.52 & 0.968 \\
0.50 & 0.064 & 95.14 & 0.981 \\
0.49 & 0.052 & 153.44 & 0.975 \\
0.48 & 0.038 & 303.88 & 0.985 \\
0.47 & 0.023 & 892.5 & 0.981 \\
0.46 & 0.006 & $14,156.7$ & 0.980 \\
& & & \\
\hline
\end{tabular}

Notes: $\bar{\pi}_{2}$ is the value to three digits which yields $\bar{h}$ nearest to 0.973 given that $\overline{f_{1} / f_{2}}$ adjusts so that $\bar{\pi}=0.45674$. See Appendix B for detalls. 
"permanent" fobs would be about 325 months or 27 years. This number is consistent with the stylized facts about the labor market. ${ }^{27} \mathrm{~A} \bar{\pi}_{2}$ of 0.112 would imply that during the recovery from a recession when $\bar{\pi}_{2}$ dominates the adjustment rate, cyclical unemployment would fall by about a ninth in one month, a third in a quarter, a half in a half year, and three quarters in a year's time if all $\phi^{\prime} s$ and $\pi^{\prime}$ s were at their normal values. Such persistence may be sufficlent to explain the puzzle of why unemployment is persistent without need for recourse to any substantially persistent expectational errors which cause $\pi_{1}$ and $\pi_{2}$ to differ from their normal values for long periods of time. This hypothesis is considered further in Section III.

A final implication of using $\bar{\pi}_{1}=.55$ and $\bar{\pi}_{2}=.112$ is that normally $79 \%$ of the unemployed would be from group 1 and only $21 \%$ from group 2.28 However, if we assume that the $\pi_{1}$ values were at their normal levels when $\pi$ fell to $0.313 \mathrm{in}$ November 1982 , then we conclude that $s_{1} / \mathrm{s}$ fell to only about 0.459 . The unemployment rate of 10.7 percent at that time can be decomposed 1nto 4.91 percentage points due to group 1 and 5.79 percentage points due to group 2. Group 1 accounts for 4.77 percentage points of the 6.07 percentage point value of $\bar{u}$, but for only 0.14 percentage points of the total 4.63 percentage points of cyclical unemployment. 29 Group 2 accounts for the remaining 1.30 percentage points of normal unemployment and 4.49 percentage

\footnotetext{
${ }^{27}$ See Hall (1982). ${ }^{28}$ This is computed as $\overline{s_{1} / s}=(0.45674-0.112) /(0.55-0.112)=0.787$. $29_{\text {We calculate }} s_{1} / s=(0.313-0.112) /(0.55-0.112)=0.459 ; \quad \overline{s_{1} / n}$ $\left(\overline{s_{1} / s}\right)(\bar{u})=(0.787)(6.066 \%)=4.77 \% ; \quad s_{1} / n=\left(s_{1} / s\right)(u)=(0.455)(10.7 \%)=$ $4.91 \%$.
} 
points of cyclical unemployment. This 1llustrates that the data are consistent with our theoretical analysis In Sections I.A and I.B: Normal unemployment consists primarily of high turnover individuals, but cyclical unemployment is dominated during the recovery from a recession by individuals who have lost "permanent" jobs and are searching for a replacement. Loss of "permanent" jobs during recessions will be more prevalent as firms in declining industries find it profitable to accelerate the eventual reductions in their labor force during such times. 30 The search process for such permanent job losers -- possibly involving relocation or shifting industries - Is a lengthy one so that cyclical unemployment falls much more slowly than would be suggested by a normal $\bar{\pi}$ of almost one half.

In this section we developed a method to characterize the extent of heterogeneity empirically using data on the duration of unemployment. We then assessed the impact of the heterogeneity in the 1953-82 period. The result is striking - that the observed heterogeneity could very well account for the observed persistence in the aggregate $\hat{\pi}$. In the next section we develop a regression model that allow us to test this hypothesis as well as characterize other cyclical determinants of $\hat{\pi}, \hat{\phi}$ and $\hat{\gamma}$.

30 This is because a reduction in the current value of the marginal product will have a disproportionately greater effect on the present discounted value of the marginal product for declining industries. Essentially, we are arguing that structural change in the economy will be greater during recessions. The basic idea is that the necessary reallocation of labor assoclated with changing tastes and technology is $11 \mathrm{kely}$ to be bunched together during recessions. This is because during these periods the value of production is relatively low and therefore this becomes an optimal time to make changes that were eventually going to be made anyway. 
III. An Empirical Model of Cyclical Unemployment

The model of unemployment rate dynamics we have developed allows us to Identify four separate potential sources of persistence in cyclical unemployment, $\hat{u}$. First, persistence could be due to the partial adjustment of $u$ toward $\bar{u}$ with $\pi, \phi$ and $\gamma$ at their normal levels. Such persistence 18 pictured in Figure 1. Our estimation of $\bar{\pi}$ in Section II imply that on average $46 \%$ of the unemployed escape unemployment each month which would 1mply that during recovery nearly half the cyclically unemployed would find fobs within a month. However, as we demonstrated empirically in Section II, the partial adjustment speed may be substantially reduced due to heterogenefty, with individual $\pi, \phi$, and $\gamma$ at normal levels. We illustrated this phenomenon in Figure 2 and the estimates we generated in Section II.C show that only about one-ninth of the cyclically employed would find jobs within a month. A third source of persistence might be autocorrelation in $\hat{\pi}, \hat{\phi}$ and $\hat{\gamma}$ due to equilibrium adjustments to changes in economic conditions. Finally, autocorrelation in $\hat{\pi}, \hat{\phi}$ and $\hat{\gamma}$ may be associated with persistent expectational errors. The first three sources of persistence are consistent with a rational expectations model of economic agents' behavior, while the fourth contradicts such a hypothesis.

In this section, we complement the measures of $\bar{\pi}, \bar{\phi}$ and $\bar{\gamma}$ developed in Section II with equations that explain the movement of $\pi, \phi$ and $\gamma$ around those normal levels and with a supplementary equation which links the movements of Inventories and money. This preliminary analysis of the data raises many questions for future research, but several messages are clear. First, heterogeneity is an important source of persistence, which confirms the empirical analysis just presented. Secondly, the data appear to be consistent with equilibrium models of persistence, with little if any role for 
autocorrelated expectational errors. Finally, within the simple model we have chosen to describe, deviations of the unemployment rate from its natural level are not caused directly by money shocks, but instead through fluctuations in the level of inventories about its mean. Thus aggregate shocks that cause the level of inventories to fluctuate, such as unanticipated fluctuations in the money supply, will affect the cyclical unemployment rate.

III.A. Behavior of the Employment Probability $\hat{\pi}$

The standard search model of unemployment states that $\hat{\pi}$ is a function of unexpected changes in aggregate demand and hence the derived demand for labor. An unexpected increase (decrease) In aggregate demand shifts the actual distribution of wage offers right (left) relative to the expected distribution so that $\pi$ is increased (decreased) relative to normal. Another, possibly complementary, theory posits that the probability of receiving any offer increases (decreases) so that the probability $\pi$ of an acceptable offer increases (decreases). Following Barro $(1977,1978)$, we use unexpected money $\widetilde{M}$ as an Indicator of shifts in aggregate demand. The strictest interpretation of rational expectations, would posit that only the current value of affect $\hat{\pi}^{31}$ We test this hypothesis by including in our $\hat{\pi}$ regression specification a distributed $\mathrm{lag}$ on the current value and first 11 lags of $\ddot{M}^{3}$

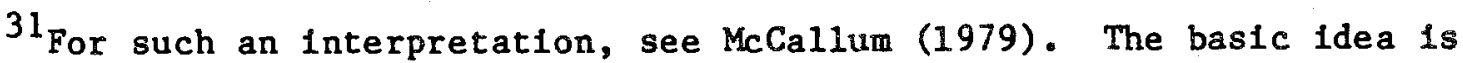
that all past information will be incorporated in current expectations and so will have no effect on real variables except through past effects on current. state variables such as inventories. If lagged values of were to enter we would conclude (a) expectations are not formed rationally, (b) the relevant horizon for forming expectations is longer than 1 month, or (c) some significant state variables have been omitted from the regression. In the latter case, the lagged coefficients would reflect past effects on the omitted state variable(s) and current effects of the state variable(s).

${ }^{32}$ We measure $\widetilde{M}$ as the residual from an $\operatorname{ARIMA}(0,2,4)$ process fit to $\log$ $M$. Our money series is the current Federal Reserve $M_{1}$ series for 1959-1 
The cyclical component $\hat{I}$ of the inventory-sales ratio may affect $\hat{\pi}$ for three reasons: ${ }^{33}$ First, our measure of $\pi$ is actually a weighted average of the probability that a searcher finds an acceptable job, the probability that a searcher leaves the labor force, and the probability that a laid-off worker is recalled. The probability of recall from layoff depends positively on the extent to which excess inventories have been eliminated. 34 Second, when inventorles are abnormally high, the discounted marginal value product of labor is abnormally low. Optimal intertemporal lelsure substitution Implies

(fn. 32 cont.) -- through 1983-12 which we have extended back to 1953-6 by a ratio splice at 1959-1 to the old $\mathrm{M}_{1}$ series in Board of Governors of the Federal Reserve System (1976). (Th1s splice preserves the growth rates in the two series which are practically identical in 1959.) After allowing for taking second differences, $\tilde{M}$ estimates are avallable from 1953-8. This start date for estimating $\tilde{M}$ was chosen for two reasons: (1) This avolds essentially all of the perlod during which the Fed was pegging government bond prices. The process determining money growth is potentially different during that period; see Friedman and Schwartz (1963, pp. 613, 625). (2) Th1s is the latest start date for $\widetilde{M}$ for which avallability of $\tilde{M}$ observations does not reduce the period over which we can estimate the regressions reported in this section.

$33_{\text {We measure }} \hat{I}$ as the deviation from a linear trend fit to Citibase data on the inventory-sales ratio for manufacturing and trade. This ratio the one-month lagged value of Business Conditions Digest series number 77 -has the beginning-of-month total book value ( 1 n 1972 dollars) of manufacturing and trade inventories as the numerator and manufacturing and trade sales for the prior month (in 1972 dollars) as the denominator. This dating is appropriate both with respect to the decision-making of the firm and for the intertemporal decision-making of individuals.

The 1inear trend was not estimated directly, but instead is that $\hat{I}$ implied by our regression of $I$ on both trend and cyclical variables (see Table 5 below). The difference is not a substantive one: The correlation cofficlent between our $\hat{I}$ and the residuals from a linear trend regression is 0.95. Deta1ls of how to 1mpute $\bar{I}$ from the Table 5 regression are given in footnote 42 below.

${ }^{34}$ See Haltiwanger and Maccinf. (1984) and Topel (1982) for theoretical results which support the discussion of the interaction of inventories and layoffs in this section. 
that some searchers should then drop out of the labor force, but we expect that in fact many of these individuals would be counted as unemployed due to unemployment benefit rules. Finally, cyclical fluctuations in inventories could shift the actual wage offer distribution relative to the expected distribution.

To capture these inventory effects, the $\hat{\pi}$ equation also includes a 12 month distributed lag on $\hat{I}$. Intertemporal substitution considerations would suggest that $\hat{I}_{-1}$ should enter because 1 is the most recent information avallable to workers during the month. From the point of view of firms, lagged as well as current values of $\hat{I}$ could enter because if there were adjustment costs associated with varying employment, it would be optimal for firms to use inventories to buffer short-run monthly variations in sales. However, given that there are also costs of varying inventories, successive monthly variations in the inventory-sales ratio in the same direction will make 1t optimal for a firm eventually to change production and hence employment. To capture this optimal lagged response of employment to inventories we include a distributed $\operatorname{lag}$ of $\hat{\mathrm{I}}$ as determinants of $\hat{\pi}$.

To capture the effects of heterogenelty on $\pi$ we use variables that Indicate how the composition of the unemployed has changed over time. In particular, we are interested in changes in the share of the unemployed who exhibit high turnover and low duration relative to the share of the unemployed who exhibit low turnover and high duration. To characterize this simply, we Include the one period lagged share of unemployed who have been unemployed less than 5 weeks as an explanatory variable in the $\hat{\pi}$ equation. The first column of Table 3 reports the results of ols regressions of $\hat{\pi}$ on the lagged unemployment share of low duration workers, and the 12 month 
TABLE 3

Determinants of $\hat{\pi}$

With $\hat{I}$ and $\tilde{M}$ With $\hat{I}$ only

Constant

Lagged Share of Unemployed with 0-4 Weeks Duration

$$
\begin{aligned}
& \hat{I} \\
& \hat{I}(-1) \\
& \hat{I}(-2) \\
& \hat{I}(-3) \\
& \hat{I}(-4) \\
& \hat{I}(-5) \\
& \hat{I}(-6) \\
& \hat{I}(-7) \\
& \hat{I}(-8) \\
& \hat{I}(-11) \\
& \hat{I}(-10) \\
& \hat{I}(-9)
\end{aligned}
$$

$-0.4588$

$(0.0112)$

$$
1.0073
$$$$
(0.0246)
$$

$-0.5677$

$(0.1296)$

0.1152

$(0.1642)$

$-0.0870$

$(0.1646)$

$$
0.1409
$$$$
(0.1648)
$$

0.1287

$(0.1653)$

$-0.1099$

$(0.1654)$

0.2245

$(0.1664)$

$-0.1341$

$(0.1656)$

0.0001

$(0.1670)$

0.1500
$(0.1675)$

$-0.0935$

$(0.1683)$

$$
0.1630
$$

$(0.1255)$
$-0.4582$

$(0.0110)$

1.0066
$(0.0242)$

$-0.6260$

$(0.1220)$

0.1557

$(0.1606)$

$-0.0481$

$(0.1605)$

0.1264

$(0.1606)$

0.0933

(0.1610)

$-0.1013$

(0.1608)

0.2135

$(0.1624)$

$-0.1044$

$(0.1616)$

0.0058

$(0.1617)$

0.1157

(0.1610)

$-0.0390$

$(0.1614)$

0.1324

$(0.1193)$ 
Table 3 (continued)

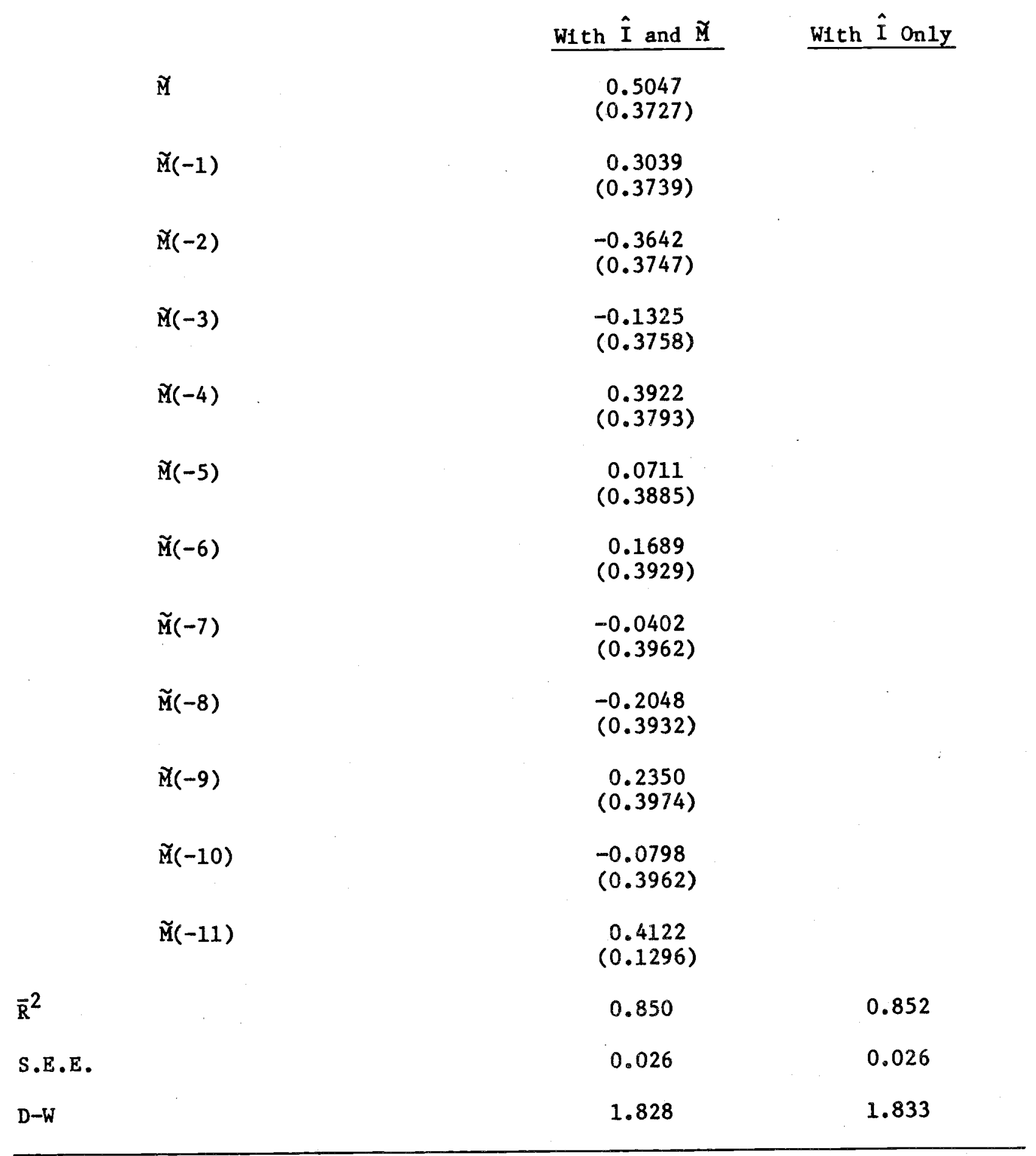

Note: Standard errors in parentheses. Period of estimation is 1954-8 through 1983-12. 
distributed lags on $\hat{I}$ and $\tilde{M}$ using oLs. The coefficients on each of the unemployment share is positive indicating that the share of the short duration unemployed as $\hat{\pi}$ increases. The coefficlent is significant at the $99 \%$ confidence level. Nelther the current money shock nor all 12 coefficients as a group are significantly different from zero. ${ }^{35}$ The coefficlent on $\hat{I}$ is negative and significant and the distributed lag on $\hat{I}$ is significant as we11.36 In the second column we report a regression which omits the insignificant lags on money shocks. The $\hat{I}$ distributed lag is now significant at the $1 \%$ confidence level. 37

We interpret these results as indicating that the primary factor determining cyclical variations in the probability of leaving unemployment is heterogeneity. Inventory innovations appear to play some role and surprisingly money shocks have no significant impact. Money shocks may be insignificant because they operate only through the $\hat{I}$ or because of measurement error problems, but there is certainly no evidence here of persistent expectational errors.

III.B. Behavior of $\hat{\phi}$

Since firings and layoffs are the complement of firms' decisions with respect to new hires and recalls, we would expect $\hat{\phi}$ to be Increased by high

$35_{\text {The }} F(12,327)$ statistic for testing the null hypothesis that all the coefficients on $\mathbb{M}$ are zero is 0.570 .

${ }^{36}$ The $F(12,327)$ statistic for testing the null hypothesis that all of the coefficients on $\hat{I}$ are zero is 2.974 .

37 The $F(12,339)$ statistic for testing the null hypothesis that all of the coefficlents on $\overline{\mathrm{I}}$ are zero $1 \mathrm{~s} 9.771$. 
cyclical inventories and decreased by positive money shocks. High inventorles or low sales due to a negative $\tilde{M}$ present the best time for firms to cull their labor force of marginal workers; when these conditions are persistent, layoffs (permanent and temporary) will result. In the opposite direction, low $\hat{I}$ and high $\widetilde{M}$ would tend to Induce firms to retain otherwise unsatisfactory workers temporarily and would reduce the aggregate incidence of new layoffs below its normal level. So as with $\pi$, we include 12 month distributed lags on $\hat{I}$ and $\hat{M}$ in our regressions explaining $\hat{\phi}$.

Heterogeneity in the labor force in terms of turnover propensities is a third factor which may influence $\hat{\phi}$. Our measure of $\hat{\phi}$ already controls for such heterogeneity that is associated with the age-sex composition of the labor force. However, other characteristics of Individuals may be related to heterogeneity in turnover propensities. In an attempt to capture some of this residual heterogeneity we include measures of the industrial composition of the labor force in the $\hat{\phi}$ regressions.

The first column of Table 4 reports the results of regressing $\hat{\phi}$ on the 12 month distributed lags on $\hat{I}$ and $\mathbb{M}$ and on the industrial composition of the labor force. The shares of the labor force by industry proved to be significant indicating heterogenelty in turnover propensities across industries. 38 Relatively high turnover industries include construction, mining and manufacturing (non-durables) whereas relatively low turnover Industries include transportation and manufacturing (durables). As a group,

${ }^{38}$ The $F(7,321)$ statistic for testing the null hypothesis that all labor force share by industry coefficients are zero is 161.39 . 
Table 4

Determinants of $\hat{\phi}$

With $\hat{I}$ and $\widetilde{M}$ With $\hat{I}$ only

Constant

LF share of Transportation

LF share of Finance and Services

LF Share of

Manufacturing-Durables

LF Share of Construction

LF Shares of Mining

LF Share of Wholesale and Retail Trade

LF Shares of

Manufacturing-Non-Durables

$\hat{\mathrm{I}}$

$\hat{I}(-1)$

$\hat{I}(-2)$

$\hat{I}(-3)$

$\hat{I}(-4)$

$\hat{I}(-5)$

$\hat{I}(-6)$

$\hat{\mathrm{I}}(-7)$

$\hat{I}(-8)$
$-0.0325$

$(0.04363)$

$-0.5475$

$(0.0966)$

0.1107

$(0.0484)$

$-0.3020$

$(0.0669)$

0.3513

$(0.0762)$

1.1473

$(0.1324)$

0.0171

(0.0850)

0.8229

(0.0590)

0.0355

$(0.0072)$

0.0187

$(0.0092)$

$-0.0062$

(0.0091)

$-0.0039$

$(0.0091)$

0.0044

(0.0092)

$-0.0078$

$(0.0092)$

0.0032

(0.0093)

$-0.0055$

$(0.0092)$

$(0.0065$

(0.0093)
$-0.0277$

(0.0425)

$-0.5295$

(0.0946)

0.1056

(0.0468)

$-0.3052$

(0.0644)

0.3474

$(0.0746)$

1.1457

(0.1298)

0.0062

$(0.0842)$

0.8054

$(0.0579)$

0.0376

(0.0067)

0.0196

(0.0090)

$-0.0077$

(0.0089)

$-0.0038$

(0.0089)

$-0.0014$

(0.0090)

$-0.0074$

(0.0090)

$-0.0024$

$(0.0091)$

$-0.0071$

$(0.0090)$

0.0079

$(0.0090)$

continued 
(Table 4 continued)

With $\hat{I}$ and $\tilde{M}$ With $\hat{I}$ only

\begin{tabular}{|c|c|c|}
\hline$\hat{I}(-9)$ & $\begin{array}{c}0.0013 \\
(0.0093)\end{array}$ & $\begin{array}{c}0.0023 \\
(0.0090)\end{array}$ \\
\hline$\hat{I}(-10)$ & $\begin{array}{l}-0.0081 \\
(0.0094)\end{array}$ & $\begin{array}{l}-0.0061 \\
(0.0090)\end{array}$ \\
\hline$\hat{I}(-11)$ & $\begin{array}{l}-0.0233 \\
(0.0072)\end{array}$ & $\begin{array}{l}-0.0210 \\
(0.0068)\end{array}$ \\
\hline$\tilde{\mathbf{M}}$ & $\begin{array}{l}-0.0012 \\
(0.0209)\end{array}$ & - \\
\hline$\tilde{M}(-1)$ & $\begin{array}{l}-0.0155 \\
(0.0210)\end{array}$ & - \\
\hline$\tilde{M}(-2)$ & $\begin{array}{l}-0.0139 \\
(0.0210)\end{array}$ & - \\
\hline$\tilde{M}(-3)$ & $\begin{array}{l}-0.0420 \\
(0.0213)\end{array}$ & - \\
\hline$\widetilde{M}(-4)$ & $\begin{array}{l}-0.0109 \\
(0.0215)\end{array}$ & - \\
\hline$\widetilde{M}(-5)$ & $\begin{array}{l}-0.0275 \\
(0.0221)\end{array}$ & - \\
\hline$\tilde{M}(-6)$ & $\begin{array}{l}-0.0102 \\
(0.0225)\end{array}$ & - \\
\hline$\tilde{M}(-7)$ & $\begin{array}{c}0.0147 \\
(0.0227)\end{array}$ & - \\
\hline$\tilde{M}(-8)$ & $\begin{array}{c}0.0165 \\
(0.0223)\end{array}$ & - \\
\hline$\tilde{M}(-9)$ & $\begin{array}{l}-0.0025 \\
(0.0226)\end{array}$ & - \\
\hline$\widetilde{M}(-10)$ & $\begin{array}{c}0.0047 \\
(0.0226)\end{array}$ & - \\
\hline$\tilde{M}(-11)$ & $\begin{array}{c}0.0217 \\
(0.0223)\end{array}$ & - \\
\hline coefficients on $\hat{I}:$ & 0.0310 & \\
\hline coefficients on $\overline{\mathrm{M}}$ : & -0.0442 & \\
\hline & $\begin{array}{l}0.790 \\
0.001 \\
1.217\end{array}$ & $\begin{array}{l}0.792 \\
0.001 \\
1.249\end{array}$ \\
\hline
\end{tabular}

Note: Standard errors in parentheses. Period of estimation is 1954-8 through 1983-12. 
the distributed lag on $\hat{I}$ proved quite significant in explaining $\hat{\phi}^{39}$ The large, significant, positive coefficients on $\hat{I}$ and $\hat{I}(-1)$ reflect the increase in layoffs associated with high cyclical inventories. It is not possible to decompose this into temporary and permanent layoffs, but the signficant negative coefficient on $\hat{I}(-11)$ suggests that variation in the rate of permanent separations for marginal workers is involved: If a marginal worker is fired earlier due to high cyclical inventories, $\hat{\phi}$ will decrease below normal levels during the latter period when the worker would have otherwise been fired. The suin of the coefficients is positive confirming the notion that high cyclical inventories cause temporary layoffs of employees who otherwise would never have been unemployed. A similar pattern of coefficients appears in the distributed lag on $\mathbb{M}$. A high value of $\mathbb{M}$ reduces the 1ikelihood that workers will be terminated in the first few months, but there is essentially no effect over a year's time as indicated by the insignificance of money shocks as a group. 40 The right-hand colum of Table 4 reports the results of a regression which drops the insignificant $\tilde{M}$ distributed lag. The " $S$ " shaped pattern of $\hat{I}$ coefficients is more pronounced than in the previous regression. Again we conclude that lagged expectational errors from money shocks account for no detectible persistence in the unemployment rate except as $1 t$ is incorporated in $\hat{I}$.

${ }^{39}$ The $F(12,321)$ statistic for testing the null hypothesis that all $\hat{I}$ coefficients are zero is 16.01 .

${ }^{40}$ The $F(12,321)$ statistic for testing the null hypothesis that all $\mathbb{M}$ coefficients are zero is 0.716 . 
III.C. Cyclical Behavior of $\hat{\gamma}$

Given potential discouraged and added worker effects over the cycle, both $\hat{I}$ and $\widehat{M}$ might influence $\hat{\gamma}$. In regressions not reported here, we tried regressing $\hat{\gamma}$ on 12 month distributed lags on these variables. The $F$ statistic on each group of parameters was insignificant and the $\bar{R}^{2}$ negligible. We conclude that, while various subgroups of the labor force may have cyclically sensitive participation rates, the overall growth rate of the labor force is not sensitive to cyclical factors.

III.D. Cyclical Behavior of the Inventory-Sales Ratio $\hat{I}$

Our results so far indicate that to understand the cyclical behavior of the unemployment rate the determinants of the inventory-sales ratio must be understood as well. Much research on the cyclical behavior of $I$ is already underway; so, for our present purposes, it suffices to estimate a simple partial-adjustment regression of $I$ on time, the lagged dependent variable, and a 12 month distributed lag on $\tilde{M}_{-1}$ as our indicator of aggregate demand shocks. Since $I$ is the ratio of beginning inventories to last month's sales, the current money shock $\widetilde{M}$ occurs too late to affect its value. This regression is reported in Table 5.

Although the equation is a simple one, it in fact explains the behavior of the inventory-sales ratio we11. The coefficient on $I_{-1}$ indicates that 9 percent of cyclical inventories are eliminated per month; this corresponds to 25 percent in three months, 44 percent in six months, and 68 percent in a year's time. The long-run effect of the time trend term is only 0.0004 per 
Table 5

Determinants of I

Constant

Time

$I_{-1}$

M: $\tilde{M}(-1)$

$\tilde{M}(-2)$

$\tilde{M}(-3)$

$\tilde{M}(-4)$

$\widetilde{M}(-5)$

$\widetilde{M}(-6)$

$\tilde{M}(-7)$

$\tilde{M}(-8)$

$\mathbb{M}(-9)$

$\widetilde{\mathrm{M}}(-10)$

$\widetilde{M}(-11)$

$\widetilde{M}(-12)$
0.0340

$(0.0072)$

0.00004

(0.00009)

0.9086

(0.0190)

$-0.4129$

(0.1583)

$-0.3672$

(0.1577)

$-0.3467$

(0.1563)

$-0.4125$

$(0.1559)$

$-0.5682$

$(0.1591)$

$-0.4715$

(0.1605)

$-0.3466$

$(0.1622)$

$-0.2325$

$(0.1657)$

$-0.3219$

(0.1655)

$-0.0832$

$(0.1664)$

$-0.1791$

(0.1686)

$-0.2422$

(0.1695)

$-3.985$

0.950

0.012

$-1.569$ 
annum. 41 The distributed lag on indicates that positive money shocks significantly decrease inventories from the first through seventh month. The gradual build up of production relative to final sales is consistent with shock-absorber money demand and costs of changing production levels. 42

${ }^{41}$ If we define $\bar{I}_{t}$ as the value to which $I_{t}$ converges in the absence of any money shocks or random disturbances; we can write $\bar{I}_{t}=\alpha+\beta t$ in this case. If in the specified regression equation, $a$ is the constant, $b$ the coefficient of time, and $c$ the coefficient of $I_{-1}$, it can be shown that the long run values are found as $\beta=b /(1-c)$ and $\alpha=\frac{a}{1-c}-\frac{b c}{(1-c)^{2}}$ The $\mathrm{bc} /(1-\mathrm{c})^{2}$ adjustment in computing $\alpha$ arises because normal growth in $\overline{\mathrm{I}}$ is conventionally included in the constant term instead of appearing explicitly in the partial adjustment mechanism. [Were it included there, we would have a partial adjustment term like $(1-c)\left(\bar{I}_{t}-\beta-I_{t-1}\right) .1$ Our estimates 1mply $\alpha=0.3682$ and $B=0.0004$.

42 on the shock-absorber approach to money demand, see Darby (1972) and Carr and Darby (1981). 


\section{Conclusions}

This paper has demonstrated that the fraction $\phi$ of the labor force becoming unemployed In a month and the probability $\pi$ of leaving unemployment over a month are useful constructs for understanding how the unemployment rate fluctuates around its normal level. Furthermore, these variables have empirical counterparts which we can readily calculate from the aggregate data on numbers and duration of unemployment.

In addition, we have shown that significant heterogenelty across Individuals in $\pi$ Implies a much slower convergence of $u$ toward $\bar{u}$ than would be hypothesized from current or normal values of $\pi$. We demonstrate that this heterogeneity is quite substantial in the aggregate data.

The hypotheses supported by our inftial exploration of these new data can be summarized by means of Figure 6. In this figure we distinguish between two groups: the first is characterized by high values of $\bar{\phi}_{1}$ and $\bar{\pi}_{1}$ compared to the second group. Money shocks do not directly affect the proximate contemporaneous determinants $\left(\pi_{1}\right.$ and $\left.\phi_{1}\right)$ of each group's cyclical unemployment rate $\hat{u}_{1}$, but do so indirectly through cyclical inventories $\hat{I}$. A restrictive monetary policy causes $\hat{I}$ to gradually build up. High $\hat{I}$ values may depress the $\pi_{1}$ directly, but their main effect seems to be on the cyclical search rates $\phi_{1}$ and $\phi_{2}$. High values of the $\hat{\phi}_{1}$ (and perhaps negative $\hat{\pi}_{1}$ ) build up $\hat{u}_{1}$ and especially $\hat{u}_{2}$ for a period of some months. Then as the effect of the money shock on inventories is attentuated, $u_{1}$ quickly returns to normal $\left(\hat{u}_{1}\right.$ goes to 0$)$. But the low turnover group is characterized by a very low normal probability $\bar{\pi}_{2}$, and this value governs the speed of adjustment of $\hat{u}_{2}$ (and eventualiy $\hat{u}$ ) toward 0 .

Indeed, it appears that in normal times the bulk of unemployment is comprised of group 1 individuals. Major recessions have the effect of 


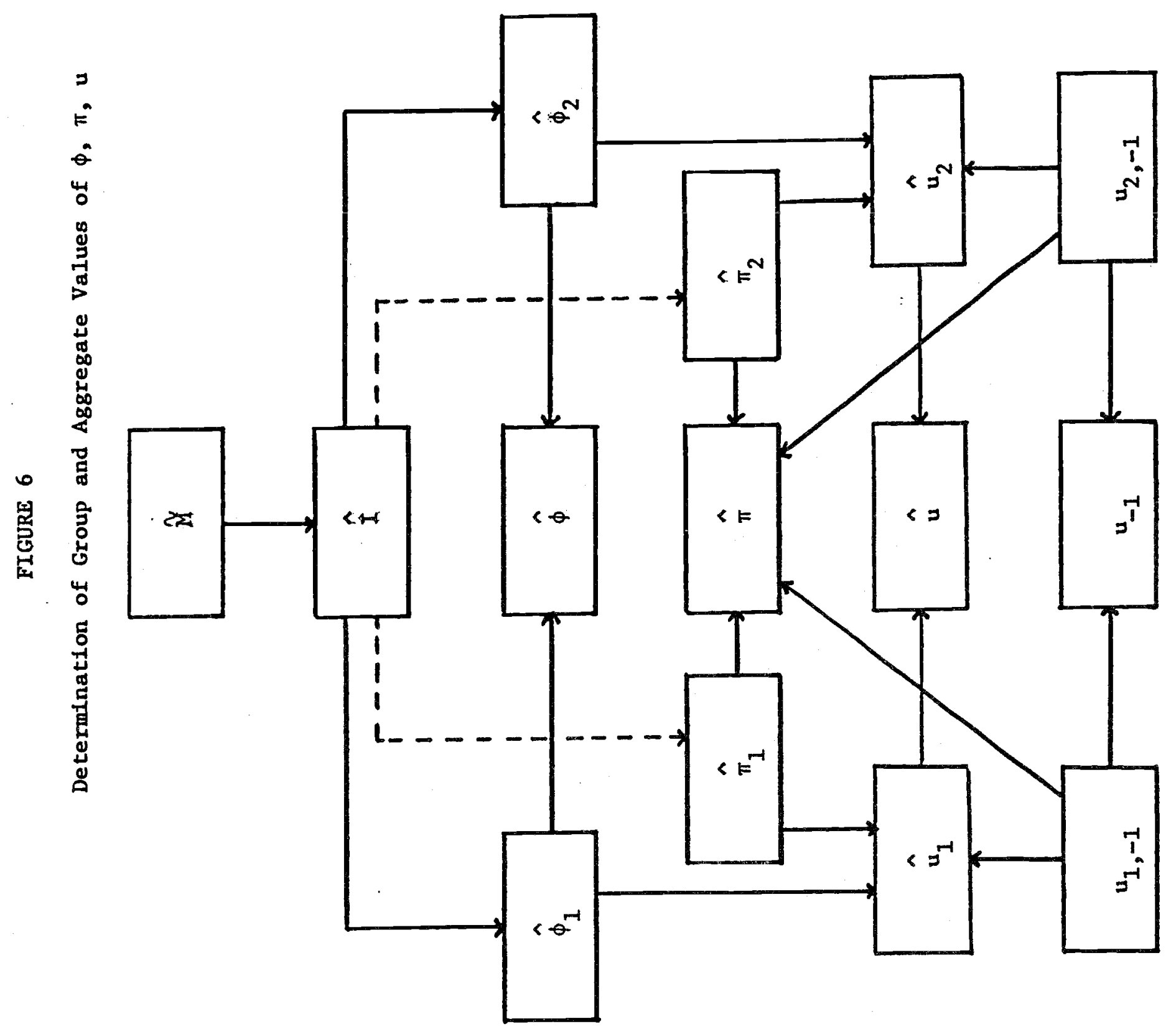


disemploylng very large numbers of group 2 individuals who otherwise have nearly permanent fobs. Thelr lengthy process of search for a new permanent job appears to dominate the recovery period and explain substantial persistence in unemployment. It is not that any individual is taking unusually long to find a fob; it is simply unusual to have so many slow searchers unemployed at once.

To return to Figure 6 , we note that given exogenous labor force shares and growth rates, we can infer the aggregate values of $\hat{\phi}, \hat{\pi}$, and $\hat{u}$ from the corresponding values for each group. At present, we are constrained to work with these aggregate data and infer compositional effects thorough proxies and other Indirect evidence. Our first task for future research w11 be to develop new measures and evidence to permit us to observe more directly the nature of labor-force heterogeneity and its influence on unemployment rate dynamics.

For now we conclude that the observed persistence in unemployment appears to be consistent with equilibrium models and rational expectations since we are unable to detect any effect of lagged -- or even current - money shocks on $\pi$. Inventories appear to be the key channel transmitting the effects of money shocks to the proximate determinants of unemployment. 
APPENDIX A

CALENDAR BIAS IN MEASURED $\pi$ DUE TO SURVEY TIMING

The potential calendar bias in $\pi$ is associated with our estimate of $s_{-1}$ which is supposed to be the number unemployed exactly one standard month ago ( 4.35 weeks). However, in months in which there are $4(5)$ weeks between surveys our estimates of $s_{-1}$ is actually the number unemployed 4(5) weeks ago. Denote $u_{-1}, u_{-1}^{4}$, and $u_{-1}^{5}$ as the unemployment rate $4.35,4$, and 5 weeks ago, respectively, and $\pi^{4}$ and $\pi^{5}$ as our estimates of $\pi$ for 4 week and 5 week intervals between surveys, respectively. Then, neglecting any growth in the labor force within a week the calendar bias is given by

$$
\pi-\pi^{4}=(1-\pi) \frac{u-1}{\left(\frac{u}{4}-1\right)}
$$

or

$$
\left.\pi-\pi^{5}=(1-\pi) \frac{u}{u_{-1}^{5}-1}-1\right)
$$

Note first that there is no calendar bias in the stationary state. Moreover, if as we belleve 18 generally the case that $(1-\pi)$ is approximately 0.5 and efther $\left(\left(u_{-1} / u_{1}^{4}\right)-1\right)$ or $\left(\left(u_{-1} / u_{-1}^{5}\right)-1\right)$ is less than 0.04 in absolute value then we can conclude that the calendar bias is negligible in magnitude. 43

43 An Increase of 1 percent (.01) per day translates into a 30 percent increase in the unemployment rate over a month. This would be 1.5 percentage points on a base of 5 percentage points. 
APPENDIX B

CALCULATIONS OF HETEROGENEITY STATISTICS

We measure heterogenelty across individual $\pi_{1}$ values by $h$, the amount by which the unemployment duration $d_{v}$ of those currently unemployed since last month exceeds 1 month plus the average unemployment duration of all persons last month $\left(d_{-1}\right)$. This $h$, which is 0 if all $\pi_{1}$ values are equal, has a statistical interpretation in terms of the covariance between duration and changes in shares by duration which can be useful for certain problems. 44 However, we need not be concerned with that interpretation to understand the derivation of Table 2 in the text.

The table is derived by considering the steady-state solution to the twogroup heterogeneity model of Section I.B. Define $\bar{\theta}_{1}$ and $\bar{\theta}_{2}$ to be the continuous time equivalents of $\bar{\pi}_{1}$ and $\bar{\pi}_{2}$, respectively. Hence $\bar{\theta}_{1}=$ $-\log \left(1-\bar{\pi}_{1}\right)$ and $\bar{\theta}_{2}=-\log \left(1-\bar{\pi}_{2}\right)$. Given $\bar{\theta}_{1}$ and $\bar{\theta}_{2}$ we can write $\bar{\pi}$ as :

$$
\bar{\pi}=\frac{\left(\bar{f}_{1} / \bar{f}_{2}\right)\left(\bar{\pi}_{1} / \bar{\theta}_{1}\right)+\left(\bar{\pi}_{2} / \bar{\theta}_{2}\right)}{\left(\bar{f}_{1} / \bar{f}_{2}\right) / \bar{\theta}_{1}+1 / \bar{\theta}_{2}}
$$

which in turn allows us to write $\left(\overline{\mathrm{f}}_{1} / \overline{\mathrm{f}}_{2}\right)$ as:

${ }^{44}$ Indeed, it can be shown that

$$
h=d_{v}-d_{-1}-1=m \operatorname{cov}\left(d_{1,-1}, \Delta \sigma_{1}\right)
$$

where $d_{1,-1}$ refers to one of the $m$ durations observed last month and $\Delta \sigma_{1}$ refers to (a) the ratio of people with duration $d_{1,-1}+1$ this month to total people with duration of one month or over minus (b) the ratio of number unemployed last month with duration $d_{1,-1}$ to the total unemployed last month. 


$$
\left(\bar{f}_{1} / \bar{f}_{2}\right)=\frac{\vec{\theta}_{1}}{\bar{\theta}_{2}} \frac{\bar{\pi}_{2}-\bar{\pi}}{\bar{\pi}-\bar{\pi}_{1}}
$$

Hence, (B2) defines the steady state ratio of inflows $\overline{\mathrm{f}}_{1} / \overline{\mathrm{f}}_{2}$ that is consistent with given values of $\bar{\pi}_{1}, \bar{\pi}_{2}$, and $\bar{\pi}$.

Define $\vec{d}^{1}$ and $\vec{d}^{2}$ to be the steady state average duration of group 1 and 2 respectfully. Then $\bar{d}^{1}=1 / \vec{\theta}_{1}$ and $\bar{d}^{2}=1 / \bar{\theta}_{2}$. Also, since all Individuals within each group are assumed to be homogeneous then $\bar{d}_{v}^{1}=\bar{d}^{-1}$ +1 and $\bar{d}_{v}^{2}=\bar{d}^{2}+1$. Define $\bar{\sigma}^{1}$ as the steady state share of unemployed from group 1. Then:

$$
\bar{\sigma}^{-1}=\frac{\left(\overline{\mathrm{f}}_{1} / \overline{\mathrm{f}}_{2}\right) / \bar{\theta}_{1}}{\left(\overline{\mathrm{f}}_{1} / \overline{\mathrm{f}}_{2}\right) / \bar{\theta}_{1}+1 / \bar{\theta}_{2}}
$$

and $\bar{\sigma}^{2}=1-\bar{\sigma}^{-1}$. This allows us to write $d$ as:

$$
d=\sigma^{1} d^{1}+\sigma^{2} d^{2}=\frac{\left(\bar{f}_{1} / \bar{f}_{2}\right) /\left(\bar{\theta}_{1}\right)^{2}+\left(1 / \bar{\theta}_{2}\right)^{2}}{\left(\bar{f}_{1} / \bar{f}_{2}\right) / \bar{\theta}_{1}+1 / \bar{\theta}_{2}}
$$

Given (B2) and the definitions of $\bar{\theta}_{1}$ and $\bar{\theta}_{2}$, (B4) allows us to compute the steady state value of $d$ associated with any combination of $\bar{\pi}_{1}, \bar{\pi}_{2}$ and $\bar{\pi}$. In a similar fashion we can define $\bar{\sigma}_{v}^{-1}$ and $\bar{\sigma}_{v}^{-2}$ as the share of last perlod's unemployed from groups 1 and 2 respectively. This, in turn, allows us to write $d_{v}$ as:

$$
\begin{aligned}
\mathrm{d}_{\mathrm{v}} & =\bar{\sigma}_{\mathrm{v}}^{-1} \overline{\mathrm{d}}_{\mathrm{v}}^{1}+\bar{\sigma}_{\mathrm{v}}^{2} \overline{\mathrm{d}}_{\mathrm{v}}^{2} \\
& =\frac{\left[\left(1+\bar{\theta}_{1}\right)\left(1-\bar{\pi}_{1}\right)\left(\overline{\mathrm{f}}_{1} / \overline{\mathrm{f}}_{2}\right) /\left(\bar{\theta}_{1}\right)^{2}\right]+\left[\left(1+\bar{\theta}_{2}\right)\left(1-\bar{\pi}_{2}\right) /\left(\bar{\theta}_{2}\right)^{2}\right]}{\left[\left(1-\bar{\pi}_{1}\right)\left(\overline{\mathrm{f}}_{1} / \overline{\mathrm{f}}_{2}\right) / \bar{\theta}_{1}\right]+\left[\left(1-\bar{\pi}_{2}\right) / \bar{\theta}_{2}\right]}
\end{aligned}
$$


Since $\overline{\mathrm{h}}=\overline{\mathrm{d}}_{\mathrm{v}}-\overline{\mathrm{d}}-1$, using (B2), (B4) and (B5) we can calculate $\left(\overline{\mathrm{f}}_{1} / \overline{\mathrm{f}}_{2}\right)$ and $\bar{h}$ for any given combination of $\bar{\pi}_{1}, \bar{\pi}_{2}$, and $\bar{\pi}$. In Table 2 we use the estimated value of $\bar{\pi}=0.45674$ and $\left(\bar{f}_{1} / \bar{f}_{2}\right)$ and $\vec{h}$ are calculated in this manner for the values of $\bar{\pi}_{1}$ and $\bar{\pi}_{2}$ as given. 


\section{BIBLIOGRAPHY}

Akerlof, George and Brian G.M. Main, "Unemployment Spells and Unemployment Experience," American Economic Review, December 1980, 70: 885-893. Barro, Robert J., "Unanticlpated Money Growth and Unemployment in the United States," American Economic Review, March 1977, 67: 101-115. , "Unanticipated Money, Output and the Price Level in the United States," Journal of Political Economy, August 1978, 86: 549-580. Barron, John M., "Search in the Labor Market and the Duration of the

Unemployment: Some Empirical Evidence," American Economic Review, December 1975, 65: 934-942. Blanchard, 0livier, "The Production and Inventory Behavior of the American Automobile Industry," Journal of Political Economy, June 1983, 91: 365400.

Carlson, John A., and Michael W. Horrigan, "Measures of Unemployment Duration as Guides to Research and Pollcy: Comment," American Economic Review, December 1983, 73: 1143-1150.

Carr, Jack, and Michael R. Darby, "The Role of Money Supply Shocks in the Short-Run Demand for Money," Journal of Monetary Economics, September 1981,8 : $183-199$.

Clark, Kım B., and Lawrence H. Summers, "Labor Market Dynamics and Unemployment: A Reconsideration," Brookings Papers on Economic Activity, $1979(1)$, pp. 13-60.

Darby, Michael R., "The Allocation of Transitory Income Among Consumers" Assets," American Economic Review, December 1972, 62: 928-941. , Lothian, James R., et al., The International Transmission of Inflation, A NBER Monograph, Chicago: University of Chicago Press, 1983. 
Diamond, Peter A., "Aggregate Demand Management in Search Equilibrium," Journal of Political Economy, October 1982 90: 881-894.

Feldstein, Martin, "Temporary Layoffs in the Theory of Unemployment," Journal of Polltical Economy, October 1976, 84: 937-957.

Friedman, Milton, and Anna Jacobson Schwartz, A Monetary History of the United States, 1867-1960, N.B.E.R. Studies In Business Cycles vol. 12, Princeton: Princeton University Press, 1963. Ha11, Robert E., "The Importance of Lifetime Jobs in the U.S. Economy," American Economic Review, September 1982 72: 724-725.

Halt1wanger, John, and L. Maccin1, "A Model of Inventory and Layoff Behavior under Uncertainty," U.C.L.A. Working Paper No. 321, January 1984. and Mark Plant, "How Should We Measure Slackness in the Labor Market?" UCLA Work1ng Paper No. 343, September 1984. Heckman, James J., and George J. Borgas, "Does Unemployment Cause Future Unemployment? Definitions, Questions, and Answers from a Continuous Time Model of Heterogenelty and State Dependence," Economica, August 1980, 47: $247-83$

Howitt, Peter, "Transaction Costs in the Theory of Unemployment," American Economic Review, March 1985 75: In press.

Leljonhufvud, Axe1, Information and Coordination, New York: Oxford University Press, 1981 .

Lilien, David M., "Sectoral Shifts and Cyclical Unemployment," Journal of Political Economy, August 19182 90: 777-793. Lippman, Steven A., and John J. McCa11, The Economics of Search, Cambridge: Harvard UnIversity Press, forthcoming 1984. and "Job Search in a Dynamic Economy," Journal of Economic Theory, 1976 12: 365-390. 
McCallum, Bennett T., "On the Observational Inequivalence of Classical and Keynesian Mode1s," Journal of Political Economy, April 1979, 87: 395-402. Rles, John C., "Unemployment in 1982: Beyond the Officlal Labor Force Statist1cs," New England Economtc Review, May/June 1984, pp. 29-37. Salant, Stephen, "Search Theory and Duration Data: A Theory of Sorts," Quarterly Journal of Economics, February 1977, 91: 39-58.

Smith, R., and J. Vansk1, "Gross Change Data: The Neglected Data Base," In National Commission on Employment and Unemployment Statistics, Counting the Labor Force, Vol. II, Washington: U..S. Government Printing Office, 1979.

Topel, Robert, "Inventorles, Layoffs and the Short Run Demand for Labor," American Economic Review, September 1982 72: 769-787. , "Equilibrium Earnings, Turnover, and Unemployment: New Evidence," Journal of Labor Economics, October 1984 2: 500-522.

Wachter, Michael L., "The Changing Cyclical Responsiveness of Wage Inflation," Brookings Papers on Economlc Activity, 1976(1), pp. 115-159. 